\title{
Mixed Projections and Syntactic Categories
}

\begin{abstract}
AUTHOR
I explore the bases of a 'distributionalist' approach to syntactic categories, i.e. an approach which makes distinctions on the basis of purely syntactic (as opposed to, say, semantic) criteria. I focus on the phenomenon of 'mixed projections', where a syntactic phrase appears to display properties of more than one syntactic category, as analysed within the framework of Lexical-Functional Grammar. I argue that of the three syntactic criteria called upon in the definition of syntactic categories within this approach only one, the internal syntactic structure of a phrase, is a sufficient criterion for syntactic categorization. This leads to a more restricted definition of category mixing, and implies a more restricted approach to categorization in general.
\end{abstract}

Keywords: syntactic categories; mixed projections; gerund; participle; masdar.

\section{INTRODUCTION}

The central topic of this paper is the criteria used for distinguishing syntactic categories, and for assigning a particular phrase to a particular category in any given instance; for example, on what basis do we assign the phrase the dogs to the category $\mathrm{N}$ (or D) as an NP (or DP), but the phrase ate biscuits to the category V (as a VP). Kornfilt \& Whitman (2011: 1297-1298) distinguish two main approaches to defining syntactic categories, one of which they label "distributionalist", the other "essentialist". The former refers to the exclusive use of syntactic criteria to define categories, while the latter refers to the use of non-syntactic criteria, such as lexical semantics, to define categories. These are not two mutually exclusive positions, of course, and some approaches to syntactic categories draw on both syntactic and non-syntactic criteria; this is the case, for example, with Baker's (2003) approach to the theory of categories. The definition of syntactic categories is a huge topic with fundamental 
consequences for the theory of grammar, a comprehensive treatment of which is not possible within the confines of this paper. Here I present a detailed exploration of the distributionalist approach to syntactic categorization, focusing on the definition of syntactic categories within a grammatical framework which is in principle fundamentally 'distributionalist': Lexical-Functional Grammar (LFG: Kaplan \& Bresnan 1982; Dalrymple 2001; Bresnan et al. 2016). The criteria used for assigning a particular phrase to a particular category are most evident in cases of apparent mismatch, i.e. when a phrase appears to show properties of more than one syntactic category. For example, in (1) the phrase his stupidly missing the penalty shows both nominal properties (possessive his, use as if a subject noun phrase) and verbal properties (object the penalty, adverb stupidly):

(1) His stupidly missing the penalty lost us the game.

Such 'mixed projections' have been the subject of recent work within LFG, revealing the use of three distributionalist criteria for distinguishing categories: ${ }^{1}$

a. Internal syntax: the internal structure of the phrase, for example whether it contains determiners, adjectives, objects, adverbs.

b. Distribution: the distribution of the phrase at a clausal level, for example whether a phrase can appear in the same structural positions, and fill the same grammatical functions, as unambiguous noun phrases, or verb phrases, etc.

c. Morphosyntax: the morphosyntactic properties of the head of the phrase, for example whether it shows the agreement features typical of a verb, an adjective, etc.

Despite the widespread use of all three criteria as independently sufficient for syntactic categorization, I argue that the evidence of mixed projections requires only the first to be a necessary and sufficient criterion for syntactic categorization

[1] Despite the terminology I adopt in (2) all three, not only the second, are 'distributionalist' in Kornfilt \& Whitman's terminology. 
within a distributionalist approach. ${ }^{2}$ Distribution and morphology are not sufficient conditions for categorization. This leaves internal syntax, i.e. differences in the internal structural possibilities of different phrase types, as the central distributionalist criterion for distinguishing syntactic categories. The narrow consequences of this are that several phenomena which have been labelled as mixed projections in LFG are not, in fact, true instances of category mixing. The broader consequences reach beyond the confines of this paper, raising wider questions regarding the use of syntactic criteria in both purely and partially distributionalist approaches to syntactic categorization.

I begin in $\$ 2$ by introducing the approach to syntactic categorization adopted in Lexical-Functional Grammar. I then focus on three (supposed) mixed projection phenomena which have been the subject of analysis within LFG: the Arabic masdar, the English gerund, and attributive participles in Sanskrit. The Arabic masdar is an example of a mixed projection which cannot be adequately analysed on the assumption that all three criteria above are independently sufficient for categorization: either distribution must trump internal syntax, or vice versa. Having proposed an analysis in which internal syntax trumps distribution, I then show that there is no need to treat distribution as a sufficient criterion for categorization in relation to the English gerund. In the case of attributive participles, both distribution and morphosyntax have been called upon as sufficient criteria for categorization, but I argue that this does not hold.

[2] By 'sufficient for syntactic categorization' in the case of mixed categories I mean taking e.g. nominal distribution of a phrase as sufficient evidence for a nominal portion of the projection of that phrase, even if there is no other evidence for nominal categorization. In the case of mixed projections, two sufficient criteria which point in contrasting directions would therefore result in a complex categorization, e.g. in a phrase which is partly nominal, partly verbal, in the sense discussed below. 


\section{SyNTACTIC CATEGORIES IN LEXICAL-FUnCTIONAL GRAMMAR}

\subsection{Lexical-Functional Grammar}

LFG is a strongly lexicalist, constraint-based framework for grammatical analysis. A crucial feature of LFG is the representation of different types of grammatical information in different 'projections'. The central levels of syntactic representation are c(onstituent)-structure, for surface constituency relations and grammatical category information, represented using the familiar 'tree' diagram, and $\mathrm{f}($ unctional)-structure, represented as an attribute-value matrix, for more abstract syntactic relations such as grammatical subject and object, and unbounded dependencies (such as between a fronted question phrase and its corresponding gap). F-structure is 'projected' from c-structure via a projection function, $\phi$, and c-structure nodes are annotated so as to constrain the formation of f-structure on the basis of c-structure. Example (3) shows the c- and f-structure for the sentence Henry likes trains, indicating the projection of f-structure from c-structure by means of the arrows betwen the two.

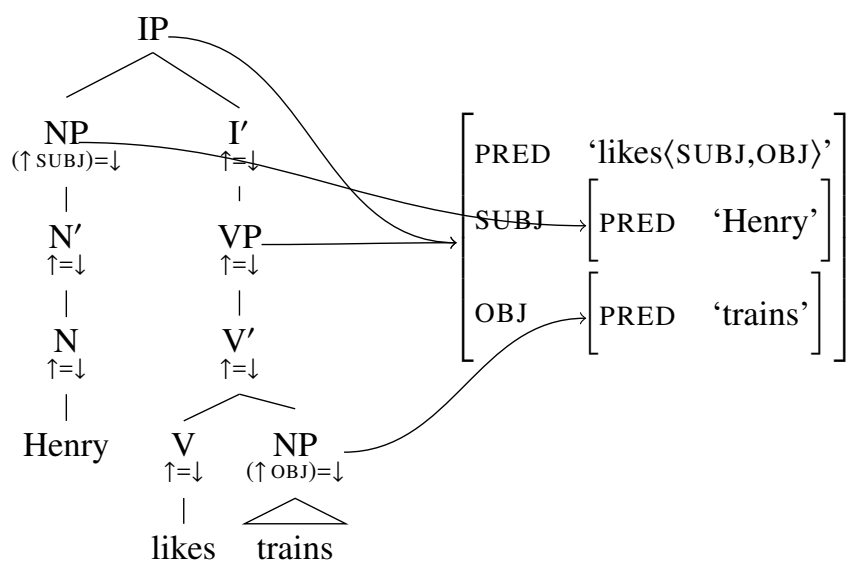

The symbols $\uparrow$ and $\downarrow$ in the c-structure annotations in (3) are metavariables, defined as in (4), where $*$ refers to the current $\mathrm{c}$-structure node and $\hat{*}$ refers to the mother of the current c-structure node.
a. $\downarrow \equiv \phi(*)$ 
b. $\uparrow \equiv \phi(\hat{*})$

So the specification ( $\uparrow$ SUBJ) $=\downarrow$ on the specifier of IP in (3) constrains the formation of the f-structure such that the f-structure projected from the phrase in SpecIP $(\downarrow)$ must serve as the value of SUBJ in the f-structure projected from the mother IP node ( $\uparrow)$. Thus the phrase in SpecIP serves as the subject of the main clausal predicate at $\mathrm{f}$-structure, as shown in (3). The specification $\uparrow=\downarrow$ states that the f-structure corresponding to the current node is the same as the f-structure corresponding to the mother of the present node. Structural headedness is understood in these terms: a head or co-head node will necessarily have the specification $\uparrow=\downarrow$.

This notion of headedness is crucial to the analysis of mixed projections in LFG. In (1) the adverb and object suggest verbal structure, but the possessive phrase implies nominal structure. The analysis proposed by Bresnan et al. (2016: 311-319), essentially identical to that of Bresnan (2001: 289-296), involves a 'head-sharing' construction whereby a VP serves as co-head complement within a DP (the DP is the 'extended head' of VP):

(5)

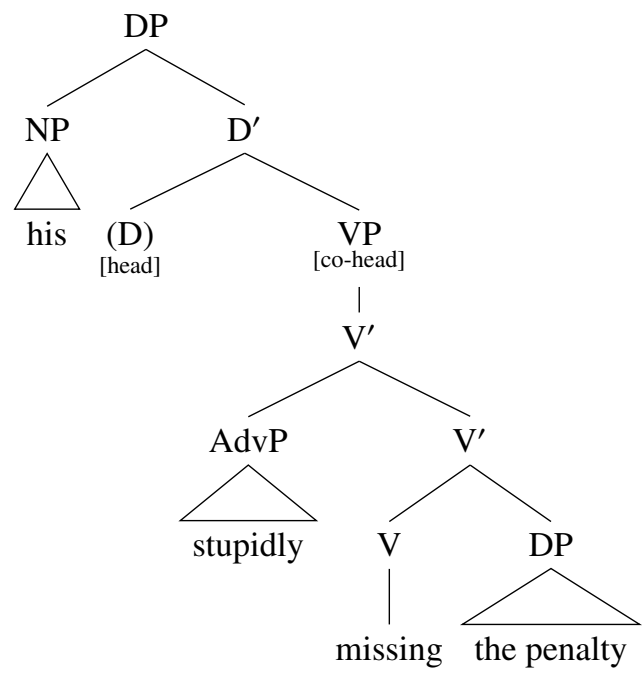

The $\mathrm{D}$ head (the categorial head) itself is absent (indicated in parentheses), but 
would, if present, be marked with $\uparrow=\downarrow .^{3}$ As a co-head, the VP has the same annotation. In (5) and subsequent trees I indicate headedness with "[(co-)head]", for explicitness.

Kaplan $(1987,1989)$ generalized the concept of projection functions, extending the scope of the framework to include additional projections representing different kinds of information, for example s(emantic)-structure as an interface between syntax and semantics (Dalrymple et al. 1996, Dalrymple 2001, Asudeh 2012), p(rosodic)-structure for representing grammatically relevant prosodic information (Butt \& King 1998, Mycock 2006, Dalrymple \& Mycock 2011, Bögel 2015), and i(nformation)-structure for the representation of information structural properties of a sentence (Butt \& King 1997, King 1997, Dalrymple \& Nikolaeva 2011). In this paper, my primary concern is syntactic categories, for example N (noun) and V (verb). LFG represents syntactic category information in the c-structure; c-structure nodes are labelled as e.g. NP or $\mathrm{V}^{\prime}$, according to category type and level of projection, based on a broadly $\mathrm{X}^{\prime}$-theoretic approach to phrase-structure. Following Kaplan (1989), the relation between a c-structure node and its label is itself a projection, although it is not usually represented as such: the label of a particular node is projected from the node via a function $\lambda .{ }^{4}$ This means that c-structure models only surface constituency relations, while syntactic category status is represented separately.

An LFG grammatical architecture, therefore, would include at least the projections in (6); the 'string', from which the c-structure is projected, represents the linguistic signal parsed into syntactic units.

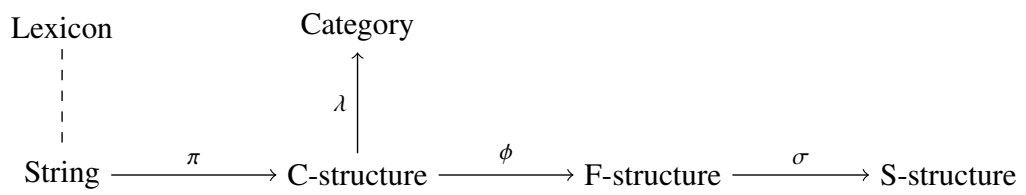

[3] For the present purposes it is a moot point whether his should appear in the specifier of DP or in D; the examples given by Bresnan et al. (2016) all involve full noun phrase possessors (Roseanne's/Mary's) in SpecDP.

[4] This projection is labelled $\chi$ by Marcotte (2014). 
The crucial point for the present topic is that different types of grammatical information are represented separately; even syntactic information is not treated as an undifferentiated whole. The use of projection functions to separate out grammatical information in this way means that the different structures, and the information contained within them, are relatively encapsulated. Syntactic categorization is therefore treated as a distinct aspect of grammar, obviously related to other aspects of grammar, but not merely an epiphenomenon of the interaction of those aspects. This makes LFG an ideal framework within which to examine the definition of syntactic categorization.

Most work in LFG assumes a finite set of major categories. For example, Dalrymple (2001: 52-54) assumes five major lexical categories, N(oun), V(erb), $\mathrm{P}($ reposition), Adj(ective) and $\operatorname{Adv}(\mathrm{erb})$, as well as the functional categories I and C. ${ }^{5}$ Other functional categories are sometimes assumed in LFG work, e.g. D, $\mathrm{K}$ (case) and Q(uantifier), as well as a number of 'minor' categories which cannot project phrases, e.g. 'Part' (particles), and one or more exocentric categories, e.g. S, which can contain a predicate along with any or all of its arguments, including the subject.

\subsection{Decomposing categories}

In this work, the only categories of concern are the major lexical categories $\mathrm{N}, \mathrm{V}$, P and $A(d j / d v)$. Bresnan et al. (2016: 103) propose that the major lexical categories $\mathrm{N}, \mathrm{V}, \mathrm{P}$ and A can be analyzed according to the following categorial feature matrix: ${ }^{6}$

[5] Throughout this paper I use Adj for the category of adjectives, and A as a cover term for Adj and Adv.

[6] This is unchanged from the earlier edition of the work by Bresnan (2001: 120), and builds on proposals by Grimshaw $(1991,2000)$. In essentials this feature matrix is the same as those proposed by Jackendoff (1977) and Chomsky (1981: 48), for criticisms of which see Baker (2003). 


\begin{tabular}{c|cc} 
& "predicative" & "transitive" \\
\hline $\mathrm{V}$ & + & + \\
$\mathrm{P}$ & - & + \\
$\mathrm{N}$ & - & - \\
$\mathrm{A}$ & + & -
\end{tabular}

'Predicative' categories require an external subject of predication, while only 'transitive' categories may govern objects. In addition to this, for Bresnan et al. (2016) categories are specified for level of projection, 0,1 or 2 (corresponding to $\mathrm{X}, \mathrm{X}^{\prime}, \mathrm{XP}$ ), and as functional (with two levels, $\mathrm{F} 1$ and $\mathrm{F} 2$ ) or not functional, which permits the inclusion of the functional categories I, C and D: I is [+predicative, +transitive] and F1, C is [+predicative, +transitive] and F2, and D is [-predicative, - transitive] and F1. Thus I and C are functional categories corresponding to the lexical category $\mathrm{V}$ in terms of the feature matrix, and $\mathrm{D}$ is a functional category corresponding to the lexical category $\mathrm{N}$ in the same terms. This feature matrix permits Bresnan et al. (2016) to state constraints on the possible combinations of functional and lexical heads; for example, they propose that NP, AdjP and PP may not function as complement to IP or CP.

This is a somewhat restricted decomposition of syntactic categories, leaving no room for a distinction between Adj and Adv (as argued for by Payne et al. 2010), and saying nothing about minor or exocentric categories. More important for the present purposes, however, is the fact that that the feature matrix in (7) is not intended as a way of deconstructing syntactic categories, but only as a way of cross-classifying them, in order to state restrictions on the combination of lexical and functional categories, or more generally as a way of permitting some categories to be grouped together in distinction from other categories. That is, N, $\mathrm{V}, \mathrm{P}$ and A remain, but we are now able to state, should we so desire, that V and A pattern together in a certain respect in contrast to $\mathrm{N}$ and $\mathrm{P}$ by virtue of their having the feature [+predicative]. Underspecification in terms of the ' $F$ ' feature is not impossible: for example, English auxiliaries may appear either in I or C, 
and similarly Hristov (2013) argues that some pronouns in English may be either $\mathrm{N}$ or D. However, underspecification in terms of the features distinguishing lexical categories is not admitted (and would in any case not be sufficient to deal with mixed projections).

\subsection{Complex categories}

Besides cross-classification across categories, there is another respect in which syntactic categories are not purely atomic in LFG. In any language, some members of a particular syntactic category are likely to differ from other members of the same category in respect of one or more properties. For example, the category V in English is standardly assumed to contain both finite verb forms and non-finite verb forms, for example infinitives, and also contains intransitive, transitive, and ditransitive verbs. The concept of complex categories (Butt et al. 1999: 192) permit generalizations to be made over a subset of members of a category. For example, we might assume a phrase-structure rule such as the following for English:

$$
\begin{array}{ccc}
\mathrm{V}^{\prime} \rightarrow & \mathrm{V} & \mathrm{NP} \\
& \uparrow=\downarrow & (\uparrow \mathrm{OBJ})=\downarrow
\end{array}
$$

Assume that at least all non-head elements on the right-hand side of a phrase-structure rule are optional, i.e. that this rule licenses either V NP or simply $\mathrm{V}$ as daughters of $\mathrm{V}^{\prime}$. If we have only an undifferentiated category $\mathrm{V}$, then the rule in (8), besides licensing grammatical structures like VPs consisting only of an intransitive verb and VPs consisting of a transitive verb and an NP complement, also licenses VPs consisting of an intransitive verb followed by an NP object complement, and VPs consisting of a transitive verb with no object complement. Of course, these ungrammatical possibilities can be ruled out at other levels of analysis: in LFG the principles of COMPLETENESS and COHERENCE require that only and all subcategorized governable grammatical functions appear in an f-structure, so that for example an NP object phrase could not appear if the governing verb does not subcategorize for one. Another 
possibility, however, is to distinguish different subcategories of the category V, so as to distinguish transitive from intransitive verbs in the phrase-structure rules. Then, instead of (8), we can assume the following:

$$
\begin{aligned}
& \text { a. } \mathrm{V}_{[\mathrm{tr}]}^{\prime} \rightarrow \mathrm{V}_{[\mathrm{tr}]} \quad \mathrm{NP} \\
& \uparrow=\downarrow \quad(\uparrow \text { OBJ })=\downarrow \\
& \text { b. } \quad \mathrm{V}_{[i t r]}^{\prime} \rightarrow \mathrm{V}_{\text {[itr] }} \\
& \uparrow=\downarrow
\end{aligned}
$$

It is still possible to refer to the category $\mathrm{V}$ as a whole in a phrase structure rule, if required; but distinguishing subcategories of $\mathrm{V}$ in this way rules out ungrammatical structures such as an intransitive verb plus an object in the phrase structure, rather than requiring reference to another level of analysis. Maxwell $\&$ Kaplan (1994) investigate the relative merits of treating such phenomena either in terms of phrasal constraints, as in (9), or in terms of functional constraints resolved by unification in the f-structure. They show clearly that distinguishing mutually exclusive classes of some major categories in the c-structure, rather than in the f-structure, is considerably more efficient in terms of parsing time. That is, from a processing perspective it is far better to eliminate major sets of impossible structures in the context-free phrase structure rules than in the unification-based feature structure. Thus it is preferable, for example, to distinguish between transitive and intransitive verbs in the phrase structure, than to leave it to the f-structure to rule out sentences like *Bill sneezed Colin and *Bill devoured. It is important to note that this does not mean there is not also a functional difference between transitive and intransitive verbs; they retain the same functional and semantic differences in terms of subcategorization, but it is computationally more efficient to distinguish them also at the phrase structure level. I assume henceforth that this approach is practically advantageous, given the importance of constraining the processing inefficiency of unification in a unification-based framework like LFG. ${ }^{7}$

[7] It could be argued that as LFG is a constraint-based framework, and therefore model theoretic 
Going beyond processing, however, there are important theoretical

considerations when it comes to deciding whether particular phenomena should or should not be modelled in the phrase structure, as well as at some other level of the grammar. Just because a particular phenomenon can be modelled in the f-structure or even semantics, does not mean it should necessarily be modelled only at that level. For example, the fact that only nouns can take determiners could be given a purely semantic explanation: the semantic contribution of a determiner is such that it can occur only with a noun, and not with a verb, adjective etc. But this fact could also be given a featural syntactic explanation (the featural contribution of a determiner is only compatible with noun phrases), and even a structural explanation (the phrase structure rules only licence Ds with NPs). In fact, all three levels of explanation may be valid: a phrase structural constraint on determiners seems eminently reasonable, but this no doubt correlates with a featural properties of noun phrases and with the semantics. Ultimately, it is preferable to model a phenomenon at multiple levels, unless there are good reasons not to: there is a methodological danger in e.g. assigning purely to the semantics phenomena which could reasonably have both a syntactic and semantic explanation, since it could be (and often is) the case that such assignments are made primarily to avoid a difficulty in the syntactic analysis, rather than on principled grounds.

Once again, processing considerations aside, it remains conceptually useful to be able to distinguish subcategories of larger syntactic categories, allowing us to increase the differentiation of syntactic categories without losing the ability to make generalizations over larger categories (such as V). It is important to note, however, that complex categories permit subcategorization within fully defined

in the sense of Pullum \& Scholz (2001), computational or processing considerations should be in principle irrelevant. It is in fact arguable whether LFG in its original formulation is model theoretic (it is taken not to be by Pullum \& Scholz 2001 and Pullum 2007), and although there are model theoretic formulations of it (Kaplan 1989 and Blackburn \& Gardent 1995), it is often presented and used as if procedural. Computational efficiency is also relevant given the huge importance of computational work within LFG, and the close relations between computational and theoretical LFG (see in particular King 2016); moreoever, insofar as LFG might even roughly be taken as a model of human linguistic competence, processing considerations matter. 
and fully distinct categories, for example sub-categories of $\mathrm{N}$ or $\mathrm{V}$, but do not permit any kind of intermediate status between $\mathrm{N}$ and $\mathrm{V}$.

\subsection{Dual categoriality}

The central issue for any approach to mixed projections is how to deal with their apparent dual categoriality. As illustrated in (5) the standard LFG approach involves a 'head-sharing' structure in which a verbal projection is embedded within a nominal projection. By the feature specifications discussed in the preceding section, $\mathrm{D}$ is a functional version of $\mathrm{N}$, and differs in categorial features from V. The structure in (5) is therefore a 'mixed' construction in a sense that a VP complementing I (as in 3) is not: in the latter case, both projections share the same category features ([+predicative, +transitive]) and differ only in terms of the functionality feature; in this case, the two projections crucially differ in terms of category features. The phrase is therefore partly nominal, partly verbal.

The type of mixed construction seen in (5) involves a lexical category serving as complement to a functional category. It is also possible, however, for a 'mixed' construction to involve a lexical category with a different lexical category as its extended head. Following Mugane (1996) and Bresnan \& Mugane (2006), Gĩkũyũ nominalizations involve a VP with NP as its extended head:

(10) muthĩnji mbũri $\tilde{u} y \tilde{u}$

1.slaughterer.NOM 10.GOAT this

'this goat slaughterer'

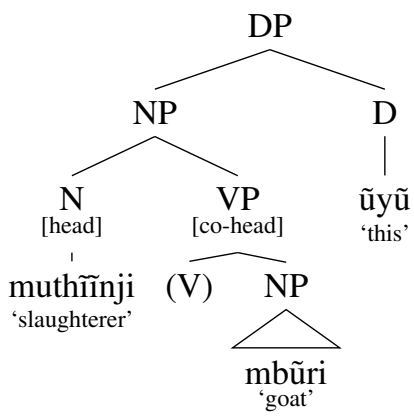


In this example, the head of the phrase, muthĩnji 'slaughterer', is categorially a noun, but also serves functionally as the head of the VP, which licenses the object phrase, here mbüri 'goat'.

Other types of head-sharing construction have also been proposed. For example, Nikitina (2008) proposes that IP may take DP as an extended head, while Bresnan et al. (2016) allow the exocentric category $\mathrm{S}$ to take DP as extended head, and similarly Nikitina \& Haug (2016) permit S to take NP as an extended head. These latter possibilities will be discussed below.

It is important to notice that the LFG approach to mixed projections violates a strict approach to endocentricity, both in the fact that words may head phrases of different categories, and in the fact that lexical phrases are permitted to lack an explicit head internal to the phrase. This is not to say that the approach is therefore not viable. Endocentricity is an important cross-linguistic tendency; in some grammatical theories it is elevated to a syntactic universal, but not within LFG. LFG adopts a relatively loose approach to $\mathrm{X}^{\prime}$ theory, conforming wherever possible, but treating $\mathrm{X}^{\prime}$ theoretic principles as violable where a particular language does not conform. ${ }^{8}$ But the fact that endocentricity is a strong cross-linguistic tendency means that its violation in the case of mixed projections should be treated as marked. For example, in the Optimality Theoretic approach to LFG developed by Bresnan (e.g. 2000), endocentricity derives from a set of universal syntactic constraints; exocentric structures may occur where competing constraints are more highly ranked, but it remains the case that all else being equal, non-endocentric structures are dispreferred in comparison with endocentric structures. ${ }^{9}$ Thus in principle (again, all else being equal), mixed projections should be admitted only where an alternative, $\mathrm{X}^{\prime}$ theoretic, analysis accounts for the linguistic data less adequately.

Bresnan (1997) contrasts her exocentric 'head-sharing' approach, illustrated in

[8] For example, LFG admits the exocentric clausal category S; it also admits ternary (or more) branching trees for certain phenomena in certain languages where linguistic evidence for binary branching is lacking (e.g. ditransitive verbs in English).

[9] This may be attributable to processing issues, as noted by Grosu \& Thompson (1977: 144). 
(5), with the 'indeterminate category projection theory' and 'projection-switching' approaches. Under an 'indeterminate' approach, the head would be underspecified such that its phrase could display features of more than one category; under 'projection-switching' approaches, as proposed e.g. by Abney (1987), Lapointe (1993), Wescoat (1994), Hudson (2003), and Malouf (2000), the head of a mixed projection is assumed to have an intermediate (rather than indeterminate) or dual category status, which enables it to project up to a certain level as if it were one category (e.g. a verb), and above that level as another category (e.g. a noun).

For example, Lapointe (1993) proposes that category labels are bipartite, the first part determining external syntactic properties such as distribution (2b), the second determining internal syntax (2a). So, Lapointe argues for an intermediate category (a "dual lexical category") $\langle\mathrm{NIV}\rangle$ to account for the English gerund, which projects verbally (ensuring verbal internal syntax), except for its top layer (ensuring it has the distribution of a noun phrase), and the -ing suffix has a morphological function in deriving a category $\langle\mathrm{NIV}\rangle$ from a plain category $\langle\mathrm{VIV}\rangle$.

More sophisticated projection-switching approaches remain the standard approach to mixed projections within mainstream transformationalist grammar. For example, Alexiadou et al. (2011) analyse nominalizations in Romance and Germanic in terms of DP projections which contain verbal functional projections; so for them, the English gerund of the type seen in (1) (their "English verbal gerund") has the structure below:

\section{(11) $[\mathrm{DP}[$ AspectP [VoiceP [vP [Root ] ] ] ] ]}

Within such an approach, nominalizations may vary as to how much verbal, and indeed nominal, structure is included in the projection. More verbal nominalizations contain more verbal projections, for example Alexiadou et al. (2011) analyse "Spanish verbal infinitives" as projecting also a Tense Phrase, in addition to the verbal projections in (11), whereas the purely nominal English gerund (their "English nominal gerund", shown in (25a)) projects only to the 
VoiceP in terms of verbal projections, while also containing additional nominal projections, such as NumberP and $\mathrm{nP}$.

Within LFG, such variation in terms of the abstract verbal/nominal features of nominalizations would not ordinarily play out in the phrase structure, but would be captured at the level of f-structure, where tense, aspect and such features are represented. Moreover the possibility of head movement within transformationalist approaches means that structures such as those in (11) may be proposed without necessitating the head to surface at the bottom of the projection; as discussed below this is not the case in LFG, which Bresnan (1997) takes as evidence (within the assumptions of LFG) against a projection-switching approach.

In the HPSG analysis by Malouf $(1996,2000)$, the mixed properties of the English gerund are accounted for by means of the multiple inheritance hierarchy for HEAD values. The HEAD value gerund is a subtype of both noun and relational. As a subtype of noun, its external distribution is that of an NP (it can "occur anywhere an NP is selected for"), and does not necessarily correspond to the distribution of verbs (which are a separate subtype of relational). Adverbial modification applies to elements of category relational (which includes adjective). Since adjectives modify only (ommon)-nouns, gerund phrases cannot be modified by adjectives. This is a sophisticated intermediate category analysis, the use of a multiple inheritance hierarchy permitting cross-classification across more than one grammatical category: it is possible to define a category that shares some features with nouns and some with verbs, without requiring it to be fully one or the other.

It would not be immediately possible to transfer Malouf's proposal into LFG, since LFG does not make use of multiple inheritance hierarchies, and does not admit mixed categories in the sense of permitting categories which are partially of one superordinate category, and partially of another superordinate category. On the other hand, it would conceivably be possible to model mixed projections using either a projection-switching approach similar to Alexiadou et al.'s, or an 
indeterminate approach. However, Bresnan (1997) argues strongly in favour of the 'head-sharing' approach, on two grounds. Firstly, there is strong evidence for the principle of 'phrasal coherence': in mixed projections "the hybrid construction can be partitioned into two categorially uniform subtrees such that one is embedded as a constituent of the other". ${ }^{10}$ There are no clear counterexamples, where e.g. a projection is mixed in such a way that no distinct verbal and nominal subtrees can be distinguished. This generalization rules out an approach to mixed categories involving an indeterminate, or underspecified, head.

Secondly, Bresnan (1997) argues that projection-switching, or intermediate, category approaches are inadequate because they require the head to be positioned in the lower projection (as in (5), where the head is in V, not D). It is important to note that this criticism applies only within the non-transformational assumptions of LFG. In a theory of phrase structure which permits movement, the surface position of the head may not correspond to its base position. But LFG assumes that constituent structure represents only the surface constituency. Thus, if we are dealing with a single projection which at some point switches from one category to another, or which displays some properties of one category and others of another while remaining a single projection, it is just a fact about phrase structure (so conceived) that the head must surface at the bottom of the projection concerned. Bresnan discusses a number of examples which show that in some languages the head must surface in the higher projection of a head-sharing structure; ${ }^{11}$ that is, the head cannot occur in the position expected under a projection-switching analysis. Thus intermediate category analyses which require the head to be in the lower position are ruled out, and the head-sharing approach, which is in other respects largely equivalent, is in this

[10] This is also discussed by Borsley \& Kornfilt (2000) and Bresnan \& Mugane (2006: 221$224)$, and is considered a "very robust generalization" by Panagiotidis (2015: 137). See also Panagiotidis (2010).

[11] In the interests of space I omit recapitulating Bresnan's arguments. An example of a phrase structure with the head in the higher projection is given in (10) above. 
respect preferable.

In this way, Bresnan's head-sharing model could not unreasonably be seen as a non-transformational variant of the mainstream projection-switching approach. In both approaches, the phrase structure involves a (e.g.) verbal projection embedded within a (e.g.) nominal projection, with the lexical head serving as the head of both projections. Since in LFG the c-structure represents only the surface constituent structure, with no movement, this abstract headship must be represented at the level of f-structure (hence the definition of head and co-head in terms of the $\uparrow=\downarrow$ annotations), and the head must be permitted to appear (i.e. be generated) in the head of the higher phrase. The other main difference between the head-sharing model of Bresnan and a standard projection-switching approach is the larger inventory of functional heads assumed in mixed projections under the latter analysis; once again this is due to the restriction of LFG's c-structure to the representation of surface constituency relations, functional properties being represented at the level of f-structure. Thus differences of framework aside, the head-sharing and projection-switching approaches are almost entirely equivalent. In this paper I adopt the head-sharing approach of Bresnan (1997). As noted also by Hudson (2003: 585) and Panagiotidis (2015: 136) the majority of theoretical models share fundamental similarities, and the differences between head-sharing and projection-switching are not crucial to the concerns of this paper. Rather, what is of primary interest is the criteria used to determine dual categoriality, however that is modelled. In almost all previous approaches, for example, distribution is taken as sufficient evidence for categorization, such that a phrase with verbal internal syntax but with the distribution of a noun phrase must have mixed categorization. The question at hand is whether this holds.

\section{THE ARABIC MASDAR}

As discussed above, work on mixed projections in LFG reveals three criteria used for categorization: internal syntax, distribution, and morphosyntax. In the default case, e.g. in the case of unexceptional noun phrases or verb phrases, these criteria 
align, and so the question of whether each of these criteria is independently sufficient for categorization, or whether one is crucial while the others merely happen to match up, does not arise. It is only when we find a mismatch between these three properties that we can begin to investigate which are truly crucial to categorization. If we find a mismatch between two properties which are both independently sufficient to justify a syntactic categorization, then we must be dealing with a phrase which has dual categoriality, i.e. a mixed projection. The default approach in existing work on mixed projections is that all three criteria under consideration are independently sufficient for categorization. However, the evidence of the Arabic masdar shows that this cannot be maintained. ${ }^{12}$ The Arabic masdar seems to be a clear instance of a mixed projection; there are two possibilities for its internal syntax, and at least one of these unambiguously involves both nominal and verbal internal syntax. However, if morphosyntax, internal syntax and distribution are all taken as independently sufficient for categorization, it becomes impossible to provide a plausible account. I begin by discussing the recent analysis of Börjars et al. (2015), who attempt to deal with the problem by disregarding the criterion of internal syntax. I show that their proposals do not provide an adequate account of the data, and I propose an alternative solution, which privileges internal syntax over distribution and morphosyntax.

Data regarding the Arabic masdar formation is provided by Fassi Fehri (1993) and Ryding (2005: 75-83). Börjars et al. (2015) distinguish two types of 'mixed' masdar construction in Arabic, although they ultimately provide one analysis that covers both. Type A is the more verbal: it can govern an accusative case object, can be modified by adverbs, and cannot be modified by adjectives:

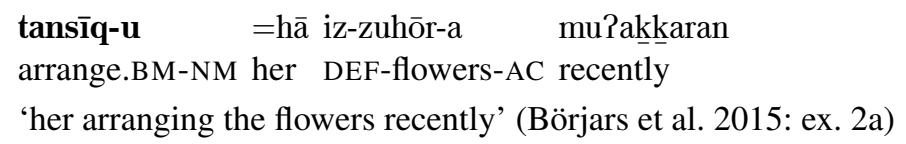

[12] Another instance is verbal nouns in Korean and Japanese, discussed by Panagiotidis (2010). 
Despite these verbal features, the phrase also has nominal features. The masdar itself shows nominal morphosyntax, being marked for case. In terms of internal syntax, the first two words in (12) exemplify the 'construct state' construction, which is a typical feature of noun phrases. The distribution of the masdar phrase is the same as ordinary noun phrases. For example, masdar phrases can function as subjects (13) and objects of verbs, and as objects of prepositions (14): ${ }^{13}$

a. zāda-t iz-zuhōr jamāl il-hafl added-FEM DEF-flowers beauty of-party 'The flowers added to the beauty of the party.'

b. zāda tansīq-u =hā iz-zuhōr-a muPaknkaran jamāl added arrange.BM-NM her DEF-flowers-AC recently beauty il-hafl of-party

'Her arranging the flowers recently added to the beauty of the party.'

a. akbara-t =na aliya an il-mušqil-a told-FEM us Aliya about DEF-problem-AC

'Aliya told us about the problem.'

b. akbara-t =na aliya an tansīq-u =hā il-mutqan-u told-FEM us Aliya about arrange.BM-NM her DEF-perfect-NM li-z-zuhōr-i mu?aknkaran of-DEF-flowers-GN recently

'Aliya told us about her arranging the flowers recently.'

Finite and other nonfinite verb phrases cannot occur in these positions. The type B masdar construction is more nominal: it shows exactly the same nominal distribution and morphosyntax, and possibility of the construct state, but in addition it does not permit objects, and does permit adjectival modification; the only verbal feature of the construction is that it also allows adverbial modification.

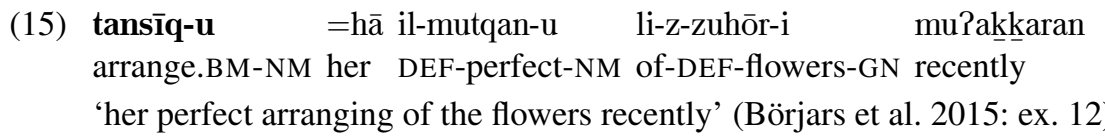

[13] For further examples see Ryding (2005: 79-83). 
Börjars et al. (2015) argue that both types A and B can be analysed in an entirely nominal structure. Since this seems most remarkable in the case of type A, I will focus on this type initially, and consider type B subsequently.

The type A Arabic masdar is mentioned by Bresnan (1997), who implies a mixed projection analysis. Börjars et al. (2015) discuss a number of possible ways in which a traditional mixed projection analysis could be implemented, but argue that none are satisfactory. The crucial problem is that the Arabic masdar appears to violate Bresnan's 'phrasal coherence' constraint, mentioned above: the nominal part of the projection does not constitute a "categorially uniform subtree" taking the verbal projection as an embedded constituent, but rather appears to be split by the verbal projection. So, if we take distribution to be a sufficient criterion for categorization, then the Arabic masdar phrase must be nominal at the top level; if we take morphosyntax and the internal syntax in the immediate vicinity of the masdar as a sufficient criterion for categorization, then the masdar itself must be of category $\mathrm{N}$, immediately surrounded by a nominal phrase. Yet the evidence of the wider internal syntax of the phrase requires (assuming that internal syntax is a sufficient criterion for categorization) a verbal projection above the nominal projection at the base of the phrase. That is, if we take all three criteria for categorization to be sufficient, we are forced to accept a structure which can be schematically represented as in (16): ${ }^{14}$

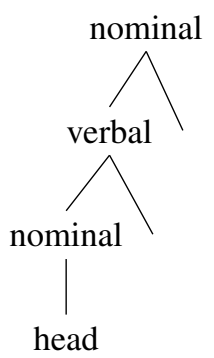

As discussed by e.g. Panagiotidis (2010), such a structure is impossible. Börjars et al. (2015) note that such a structure would be unparalleled and therefore relax

[14] Note that this would also be the case if the criterion of morphology were disregarded. 
the criteria for categorization in order to produce a more acceptable structure. They do not question the assumption that morphosyntax and distribution are sufficient evidence for categorization, meaning that the masdar phrase must be nominal at the top and at the bottom. Given that, the only way to avoid the implausible structure in (16) is to discount the criterion of internal syntax, and to analyse the phrase as nominal all the way through, despite the fact that it can contain objects and adverbial modifiers. ${ }^{15}$

Börjars et al. therefore argue that differences in internal syntax do not serve to distinguish categories; for example, they claim that object phrases and adverbial adjuncts can appear inside NPs just as they can within VPs. The structure they propose for the phrase in (12) is given below: ${ }^{16}$

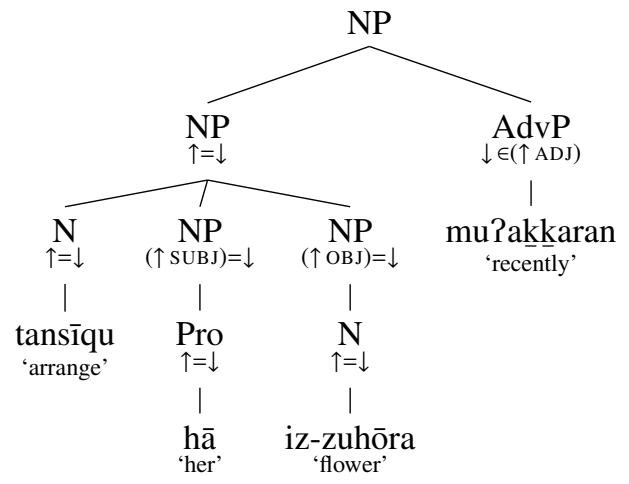

In this structure, adverb phrases are licensed as adjuncts within NPs, and objects are licensed as complements of $\mathrm{N}$. Thus distribution, and to an extent morphosyntax, are given priority over internal syntax in their analysis: verbal internal syntax does not necessitate a verbal projection, largely because of the distributional facts (because the nominal distribution rules out a verbal

[15] As noted above, Korean and Japanese verbal nouns present a similar problem. As pointed out to me by a reviewer, Panagiotidis (2010) attempts to deal with the problem in Korean and Japanese by treating such verbal nouns as noun-to-verb zero conversions inside a mixed projection. I will not consider this possibility further here, since it could not easily be converted into an LFGbased analysis.

[16] Börjars et al. (2015) assume that there is no DP in Arabic, and that there is no intermediate bar-level of projection between X and XP. I follow these assumptions below; nothing depends on them. 
projection, when taken together with the nominal internal syntax at the base of the phrase).

Turning now to the type B masdar, Börjars et al. (2015) propose that the same set of rules that license the type A masdar, together with general rules of noun phrase formation (such as adjectival modification), license the type B masdar, which is under their analysis fully nominal, just like the type A masdar:

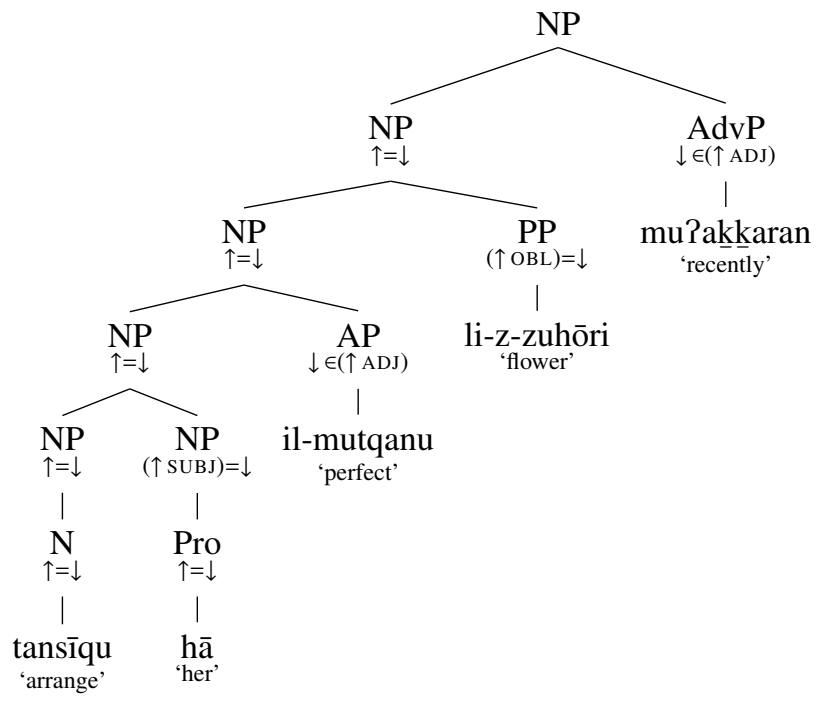

While Börjars et al.'s proposal provides a categorially uniform, and thus in certain respects attractive, analysis of the Arabic masdar, it suffers from both theoretical and empirical weaknesses. On the empirical side, the rules provided by Börjars et al. (2015), and illustrated in the trees above, fail to capture an important constraint on the type B masdar: adjectival modifiers must appear closer to the head than adverbial modifiers. Börjars et al. (2015) treat both adjectival and adverbial modification by means of adjunction inside NP, so they cannot constrain the order of such adjuncts structurally.

Moreover, the crucial structural restriction distinguishing the type A and B masdars is not accounted for under Börjars et al.'s proposal: adjectives and objects may not appear within the same masdar phrase. The type A masdar may have objects, but not adjectives, while type B may have adjectives, but not 
objects. This constraint is not accounted for structurally by Börjars et al.: in principle any noun phrase may be modified by an adjective (or an adverb), or govern an object. Börjars et al. (2015) assume that the restriction on adjectival modification can be enforced by the semantics: the semantic core of the type A masdar is inherently more propositional, making it inappropriate for modification by adjectives. But this does not in itself explain why objects are possible only with the more propositional type A, nor does the very reasonable suggestion that there is a semantic angle to the restriction necessarily eliminate the advantage of providing a syntactic account. ${ }^{17}$

On a more theoretical level, if we eliminate internal syntax as a criterion for distinguishing between categories, we run into the problem of how to capture the usual internal syntactic distinctions between categories. For example, the fact that the vast majority of noun phrases cannot govern structural objects and cannot be modified by adverbs, can no longer be accounted for structurally. Rather, Börjars et al. (2015) assume that subcategorization and/or semantics will effect the constraints (for example, adverbs are only semantically appropriate as modifers of words with an event argument). While theoretically possible, the huge proliferation of ungrammatical phrase structures licensed by Börjars et al.'s proposal, such that any noun could appear with a structural object and adverb modifier (until ruled out by functional/semantic considerations), runs counter to the principle, discussed above, that it is better to rule out impossible structures in the context-free phrase structure component of the grammar. For a plausible analysis of the Arabic masdar we cannot maintain that internal syntax, distribution and morphosyntax are all independently sufficient for categorization. Since the rejection of internal syntax as a criterion, as proposed by Börjars et al. (2015), does not lead to an adequate analysis, it is necessary to seek an alternative. Let us assume that internal syntax is crucial to categorization.

[17] That semantic distinctions are crucial to understanding syntactic differences between different types of nominalization has been known for a long time. See e.g. Grimshaw (1990); Börjars et al.'s distinction is based on the proposals of Hamm \& van Lambalgen (2005). 
We will therefore assume that the phrase structure rules distinguish different categories in terms of the types of specifiers, complements and adjuncts that they admit. So I assume standard phrase structure rules for noun phrases which license determiners, adjectival modification, but not (general) adverbial modification or object complements, whereas the standard phrase structure rules for verb phrases license / exclude the converse.

The internal syntax of the construct state suggests that the base of the masdar phrase is nominal, and the nominal morphosyntax of the masdar supports this. The evidence for verbal internal syntax, i.e. the possibility of an object phrase with the type A masdar, and the possibility of adverbial modification with both types, requires also a verbal projection dominating the nominal projection. Given that we do not want a further nominal projection on top of this, we can have no more structure than this: the masdar phrase is a mixed projection, NP at the bottom, VP at the top. That is, I propose the following in place of (17):

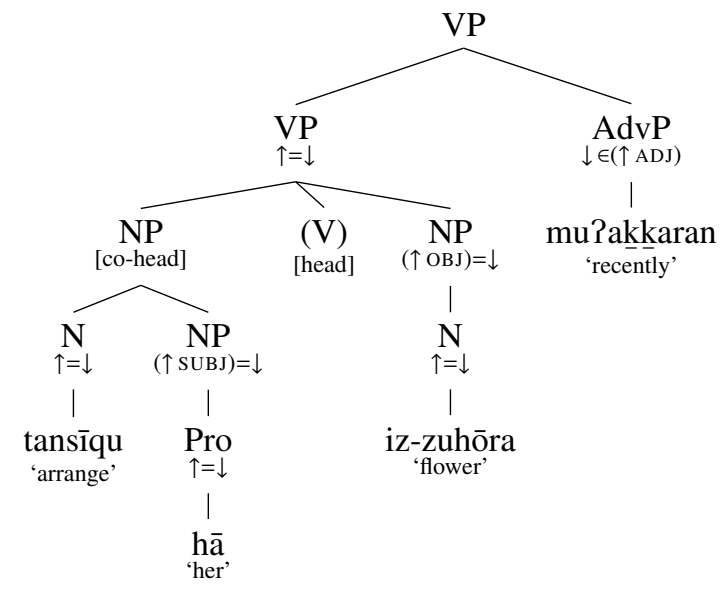

The internal structure of this phrase fits the data, and standard LFG phrase structure assumptions, perfectly. The adverbial modifier is an adjunct within the verbal projection. The object phrase is a sister to the position which would be the lexical head of the VP, if it were not empty; to this same (null) position, the embedded NP co-head phrase is a sister, just as expected for a co-head phrase. The only unusual aspect of this analysis is the category of the top node. The 
distribution of the masdar phrase is nominal, yet this phrase is a VP. The necessary conclusion, then, is that if internal syntax is crucial to categorization, distribution cannot be crucial to categorization. We are left, then, with an analysis which requires a subset of VPs (those headed by masdars) to have the distribution of noun phrases.

Ordinarily, perhaps, distributional identity is correlated with categorial identity, which explains the widespread sense that distribution is a useful criterion for categorization. However, in a constraint-based framework, there is no reason why this should necessarily be the case. As discussed for example by Pollard (1996), it is important to draw a conceptual distinction between the means used to capture syntactic generalizations (such as phrase structure rules and functional descriptions) in a grammar and the syntactic structures licensed by that grammar. ${ }^{18}$ The grammar consists fundamentally of a set of constraints; the constraints are the crucial element, not the resulting structures. Grammatical structures are required to satisfy the constraints, but there is no requirement that any structure should necessarily visibly reflect every constraint that it satisfies. In LFG, the phrase-structure tree (the c-structure) is one part of the syntactic structure licensed by the grammar, the part which models surface phrasal constituency. The primary means for capturing syntactic generalizations are the phrase structure rules. Only to the extent that the c-structure directly reflects the generalizations made in the phrase-structure rules does the c-structure itself represent those generalizations, and there is no requirement that any one rule should be directly reflected in the c-structure. In fact, the LFG formalism specifically licenses a distinction between phrase-structure rules and associated phrase-structure trees, in the form of metacategories and phantom nodes (Dalrymple 2001: 94-95). It is the concept of metacategories which are of relevance here. The most obvious use of a metacategory is to generalize over more than one category which can appear in the same position. For example,

[18] I am grateful to Ron Kaplan (p.c.) for advocating this distinction to me. 
English verbs like consider can take predicative complements of at least four different categories:

a. Bill considers me $[\text { lucky }]_{\mathrm{AP}}$.

b. Bill considers me [a reprobate $]_{D P}$.

c. Bill considers me [out of danger $]_{\mathrm{PP}}$.

d. Bill considers me [to lack courage $]_{\mathrm{CP}}$.

All four structures can be accounted for using the same phrase structure rule (22), granted the metacategory definition in (21).

(21) $\mathrm{XP} \equiv\{\mathrm{AP}|\mathrm{DP}| \mathrm{PP} \mid \mathrm{CP}\}$

(22) $\mathrm{V}^{\prime} \rightarrow \mathrm{V}$ DP XP

A metacategory definition serves to capture syntactic generalizations just as an ordinary phrase-structure rule does, but the difference is that the metacategory definition does not result in a corresponding representation in the phrase-structure tree. ${ }^{19}$ The situation with the Arabic masdar, under the analysis proposed here, is equivalent: masdars share their distribution with noun phrases, but are not noun phrases themselves. If we use a complex category $\mathrm{V}_{\text {[msd] }}$ to distinguish masdar VPs from finite VPs, we can capture the identity of distribution between NPs and masdar VPs unproblematically using a metacategory:

$$
\mathrm{NomP} \equiv\left\{\mathrm{NP} \quad \mid \quad \mathrm{VP}_{[\mathrm{msd}]}\right\}
$$

This constraint enables the identity of distribution between masdar VPs and noun phrases to be captured in the PS rules, just as well as it could under an analysis in which the masdar phrase was an NP at its head, but with the additional advantage that it does not require the masdar phrase itself to be an NP at its head, a requirement which we have seen leads to analytical difficulties.

[19] That is, there will be no ' $\mathrm{XP}$ ' node in a c-structure representing (22), rather the rightmost daughter of $\mathrm{V}^{\prime}$ will be one of AP, DP, PP or CP. 
As discussed above, the proposal of Börjars et al. (2015) suffers from two empirical weaknesses: it provides no account of the constraint that adjectival modifiers must appear closer to the head than adverbial modifiers, and it provides no account of the fact that objects and adjectival modifiers may not cooccur in the same phrase. Under the analysis proposed here, the first constraint follows unproblematically. AdvP adjuncts are licensed within VP, while AdjP adjuncts are licensed within NP, meaning that the latter are necessarily closer to the head than the former. The type B masdar (15), which permits both adjectival and adverbial modification, must therefore also be a mixed projection, with the same VP-over-NP structure as the type A masdar:

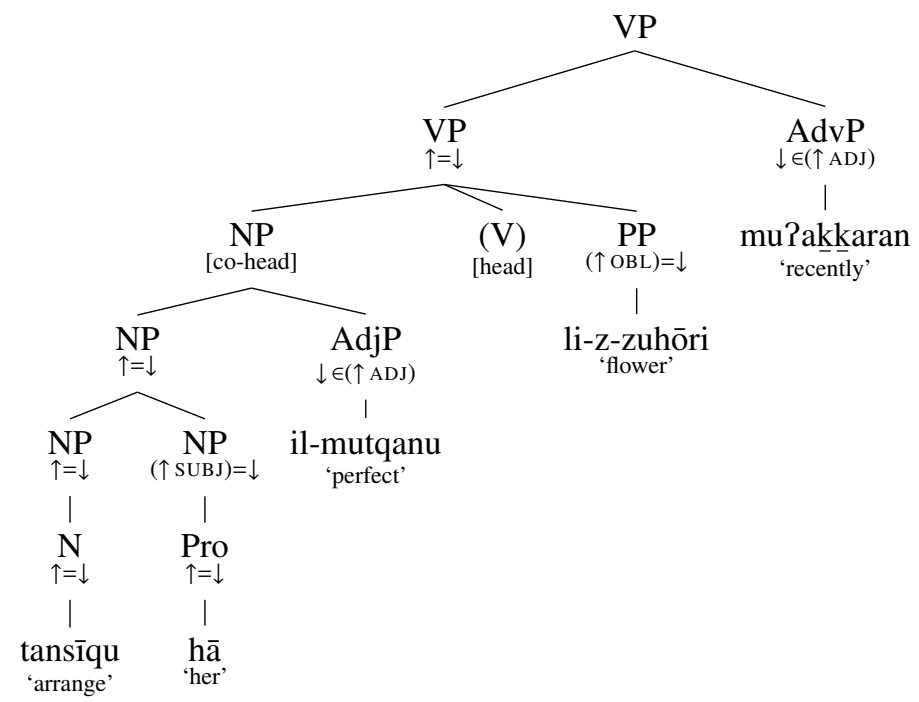

Once again the structure of this phrase fits standard phrase structure assumptions. The oblique complement is sister to the empty verbal head, as is the co-head NP. The adjectival modifier occurs within the NP, which means it necessarily precedes the adverbial modifier within VP. Once again, the nominal distribution of this VP must be captured in the phrase structure rules; the same constraint (23) which captures the distribution of the type A masdar applies equally to type B. In fact, just as assumed by Börjars et al. (2015), there is no need to treat the type A and type B masdars as differing in any way at the level of phrase structure. The 
superficial difference between them, that type A may have an object, and may not be modified by adjectives, while type B may be modified by adjectives, but may not have an object, can be captured by a cooccurrence constraint preventing adjectives and objects from appearing together in the same phrase. Under Börjars et al.'s approach, there is no way to model the constraint in the syntax, hence their relegation of the phenomenon to the semantics. Under the analysis proposed here, however, this constraint can be captured with relative ease: objects must occur closer to the head than adjuncts. Since in the structures proposed above (19 and 24) objects can only occur within the verbal part of the projection, and AdjP adjuncts only within the nominal part, if an object and an adjective were to co-occur, the adjective would necessarily occur closer to the head than the object. The proposed constraint, which rules out such a structure, correlates with the semantics: objects are core arguments, more central to the meaning of a predicate, and hence more naturally appear closer to the head, in structural terms, than an adjunct. ${ }^{20}$

Thus the mixed projection analysis proposed here, which takes internal syntax as of primary importance for categorization, provides a more thorough account of the Arabic masdar data than the proposal of Börjars et al. (2015), which downplays the evidence of internal syntax for categorization, depending rather on distributional and morphosyntactic criteria.

\section{The English Gerund}

The evidence of the Arabic masdar shows that it is not possible for all three criteria in (2) to be independently sufficient for categorization. My proposed analysis of the Arabic masdar takes internal syntax to be crucial for categorization, with the consequence that distribution is not a sufficient criterion for categorization. Distribution has been taken as a sufficient criterion in work on

[20] Since the head of the masdar phrase must be first in the phrase, this constraint can be formalized in terms of linear precedence, which can be unproblematically stated in LFG by reference to 'f-precedence' (Kaplan \& Zaenen 1989); for example, for any f-structure $m$, if ( $m$ VFORM $)=$ MASDAR, then $(m$ OBJ $)<_{f}(m$ ADJ $)$. 
other mixed categories, including the English gerund in -ing. In this section I show what the consequences of my proposals are for the analysis of the English gerund.

\subsection{Introduction}

The standard LFG approach to mixed projections was developed by Bresnan (1997, 2001: 289-296) and Bresnan \& Mugane (2006), who discuss the English gerund in -ing, undoubtedly the most commonly discussed mixed projection. ${ }^{21}$ In fact, the English gerund is a particularly complicated example, because there are three different phrasal configurations in which the gerund may appear. The English gerund can display either entirely nominal, entirely verbal, or 'mixed' phrasal structure:

(25) a. His stupid missing of the penalty lost us the game.

b. Him stupidly missing the penalty lost us the game.

c. His stupidly missing the penalty lost us the game.

I refer to these as types $\mathrm{A}, \mathrm{B}$ and $\mathrm{C}$ respectively. In all these examples, the gerund heads a phrase which functions as subject of the sentence. In type A (25a), the syntax of the phrase headed by missing is entirely nominal: the semantic object of missing appears as a prepositional complement, as is standard for complements of nouns; missing is premodified by an adjective, as only nouns can be; and the phrase also contains a possessor phrase, a possibility only found within nominal projections. Although the form missing is derived from the verb miss, the exclusively nominal syntax of the phrase means that missing here can be unambiguously analysed as a noun, i.e. of category $\mathrm{N}$, heading an entirely unremarkable NP. ${ }^{22}$

[21] Mixed categories have been the subject of a number of works within LFG; see also Bresnan et al. (2016: 309-319), Spencer (2004), Seiss (2008), Nikitina (2008), and Alsharif (2014). Most recently, Spencer (2015), Börjars et al. (2015) and Nikitina \& Haug (2016) have discussed phenomena which they analyse in terms of mixed projections.

[22] $\widehat{\mathrm{Adj}}$ is a 'non-projecting' category (Toivonen 2003), an Adj which cannot project a full phrase (Sadler \& Arnold 1994, Arnold \& Sadler 2013). This non-projecting analysis of English 


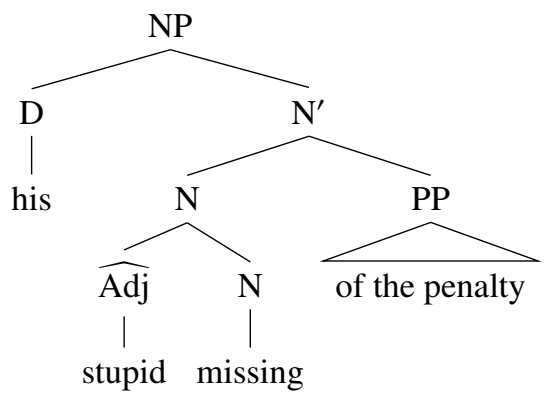

The type A gerund type seen in (25a) is therefore not a mixed projection, and will not be considered further. In contrast, the syntax of the phrase headed by missing in (25b) is entirely verbal: the semantic object appears in the same form as an object of a finite verb, i.e. 'bare' (not embedded under a preposition); the semantic subject likewise appears in the 'bare' form, with oblique/accusative 'case'; and the modifier is an adverb. I call this type B; it is commonly referred to as the "Acc-ing" construction. This type will be discussed below where I argue, contrary to standard analyses, that it is not a mixed projection.

The unambiguously 'mixed' construction is type $\mathrm{C}$ (commonly referred to as the "Poss-ing" construction), exemplified in $(25 \mathrm{c}=1)$ : the internal syntax of the phrase headed by the gerund is mixed, in that the phrase contains elements which are specific to DPs in English (possessive modifier) and elements which are specific to VPs in English (object and adverb modifier); the distribution of the phrase is at least superficially nominal, since it can function as a subject (as in the example provided), object, or other grammatical function, or indeed can appear in any of the positions in a clause as an ordinary noun phrase can; in terms of morphology, the type $\mathrm{C}$ gerund in -ing cannot show plural marking (*their missings the penalties, vs. type A their missings of the penalties), and does show the same kind of tense/aspect distinctions as finite verb sequences (cf. his having missed the penalty... ), which suggests closer affinities with the verbal system than the nominal system. The analysis proposed by Bresnan et al. (2016: 
311-319) was given in (5) and is repeated in (27).

(27)
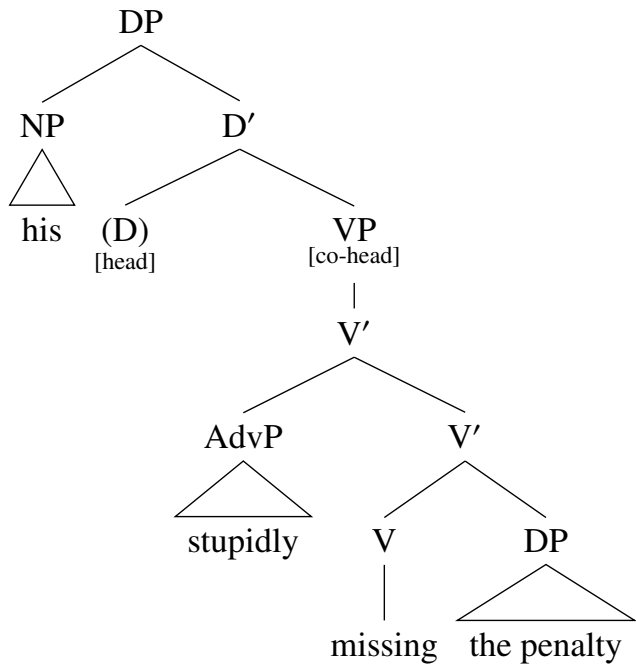

\subsection{Distribution and the type $B$ gerund}

As discussed above, I take internal syntax to be crucial to categorization.

Therefore the fact that the type $\mathrm{C}$ gerund shows both nominal and verbal internal syntax means that it must be treated as a mixed projection, just like the Arabic masdar. I therefore accept Bresnan et al.'s analysis (27) for the type $\mathrm{C}$ gerund. On the other hand, the type B gerund is consistently verbal in terms of its internal syntax, as well as sharing the same verbal morphosyntactic properties as the type $\mathrm{C}$ gerund. The following table compares the relevant properties of the Arabic masdar and the type $\mathrm{B}$ and $\mathrm{C}$ gerunds:

\begin{tabular}{|l|c|c|c|}
\hline & Internal Syntax & Distribution & Morphosyntax \\
\hline Arabic masdar & mixed & nominal & nominal \\
Eng. B Gerund & verbal & nominal & verbal \\
Eng. C Gerund & mixed & nominal & verbal \\
\hline
\end{tabular}

The type C gerund shows two distinct types of property 'mixing': firstly the three criteria in (2) point in different directions, e.g. distribution points towards 
nominal status, morphosyntax points towards verbal status; secondly, the criterion of internal syntax itself points in more than one direction. In this way the type $\mathrm{C}$ gerund is similar to the Arabic masdar, the only difference being that with the former the evidence points to NP-over-VP, while with the latter the evidence points to VP-over-NP. In contrast to these constructions, the type B English gerund construction (25b) is more consistently verbal: it is morphologically verbal in exactly the same way as the type B gerund, and its internal syntax is purely verbal. Its only potentially non-verbal property is its distribution: it shows the same apparently nominal distribution as the type $\mathrm{C}$ gerund. Despite these differences Bresnan et al. (2016: 318) treat the type B gerund via the same kind of head-sharing analysis as the type $\mathrm{C}$ construction (25c), the only difference being the category of the co-head phrase:

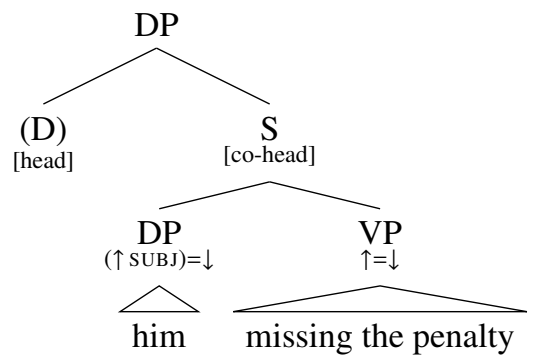

As with (5) above, the gerund appears in the head of a VP, with object complement like any transitive V, but in this case the VP and accusative case subject phrase him together constitute a clausal phrase $\mathrm{S}$, which serves as co-head complement of (absent) D in the higher DP. Thus the phrase as a whole is a DP, headed by a V in an embedded VP, just as in (5). It is clear that the DP node, and therefore the mixed projection analysis altogether, depends entirely on the assumption that nominal distribution is sufficient evidence for a nominal projection in the phrase structure.

The S node in (29) is an exocentric category, often utilized within LFG for phrases containing a verb (phrase) and the verb's subject. Thus, the analysis shown in (29) involves two instances of exocentricity: the exocentricity of S, and the exocentricity of the extended head structure. The use of S is not strictly 
relevant for the present discussion, and it could be eliminated, by licensing the subject phrase in Spec,VP, and thus having simply a VP complement of D. Under Bresnan et al.'s proposal, the S node is required only if there is an accusative case subject; if there is no subject, there is simply a VP with DP as extended head (ambiguous between the (25b) and (25c) types). Bresnan et al. (2016: 318) derive the S-less structure by Economy of Expression, a derivational process which effectively 'prunes' unnecessary nodes from trees. Given the rejection of Economy of Expression by Dalrymple et al. (2015), it is preferable to follow Seiss (2008) in assuming that the daughter of DP in the type B gerund is consistently a VP, with the subject phrase appearing in SpecVP. That is:

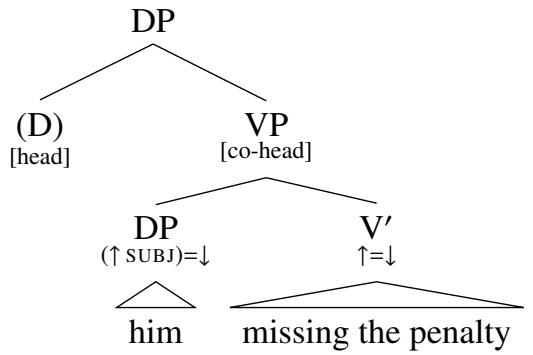

Nevertheless, the category of the verbal node is not the crucial point here. What matters is the top DP node: the internal syntax of the phrase is entirely verbal (or clausal): there can be no adjectival modifier, or determiner or possessor phrase. Given that there are no explicit morphological properties of the gerund that require a DP node, it is clear that the DP node is assumed purely to account for the distribution of the phrase, i.e. distribution is taken as a sufficient criterion for postulating a syntactic category.

There exist a number of similar proposals for mixed projection analyses that take distribution as a sufficient criterion for categorization. For example, as discussed in more detail below, Bresnan (1997) and Spencer (2015) propose that attributive participial clauses, which show the internal syntax of a VP but the distribution and agreement features of an Adj, are best analysed via a mixed projection in which a VP functions as complement to AdjP. Similarly, Haug \& Nikitina (2016: 15) assume a head-sharing construction for a participle construction in Latin (the 
'dominant' participle construction) which shows the external syntactic distribution of a noun, but whose internal syntactic structure is that of an S. ${ }^{23}$ Since Latin lacks a DP, they assume an S as a co-head complement of an NP:

(31) $a b$ urbe condita

from city.ABL.SG found.PST.PTC.ABL.SG.FEM

'from the founding of the city' (lit. 'from the city having been founded')

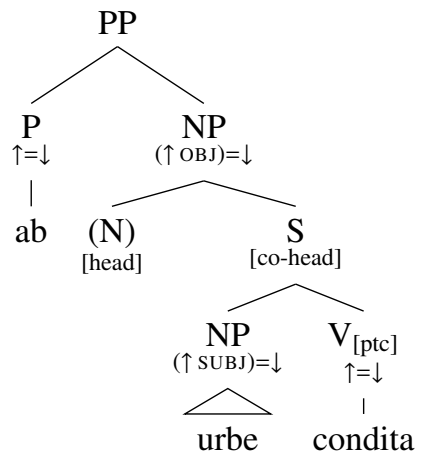

The NP projection above S in (32) might predict that the phrase itself could contain nominal syntactic structure, but this is not the case. The dominant participle phrase as a whole, i.e. what Nikitina \& Haug (2016) and Haug \& Nikitina (2016) demonstrate is an S, cannot be modified by an adjective, for example. Again, the only justification for the NP projection above $\mathrm{S}$ is the distribution of the phrase.

Distribution alone, then, is taken as sufficient evidence for categorization within LFG work on mixed projections. But as I have shown above, this assumption cannot be maintained in the case of the Arabic masdar. In that case, it appeared preferable to disregard the evidence of distribution, which can be accounted by other means, in favour of internal syntax as the primary criterion for categorization. The same argument can in fact be made for the English type B gerund.

A number of authors, including Abney (1987) and recently Pires (2007: 167-168), note certain differences between the type B and type C gerunds which 
bring into question the assumption that both involve a nominal projection at the top level. Specifically, the type B gerund shares certain properties with finite clauses which are not found with the type $\mathrm{C}$ gerund (poss-ing). For example, the type B gerund is compatible with wh-extraction, expletive subjects, and certain adverbs, which are not possible with the type $\mathrm{C}$ gerund (examples from Pires 2007):

a. Who did you defend Bill(*'s) inviting?

b. You may count on there (*'s) being a lot of trouble tonight.

c. Mary(*'s) probably being responsible for the accident, the attourney did not want to defend her.

Gerunds without an overt subject, which are superficially ambiguous between type $\mathrm{B}$ and $\mathrm{C}$, pattern with type $\mathrm{B}$ in all cases where the difference is not neutralized. None of this data can be accounted for under the proposals of Bresnan et al. (2016), according to which both types are mixed projections with the same top node. However, if we abandon the assumption that nominal distribution is sufficient evidence to require a nominal projection, it is possible to treat the type B gerund (including gerunds without overt subjects) as a purely verbal projection. Then the fact that the type $\mathrm{C}$ gerund is less clause-like than the type B gerund can follow from the fact that type C, but not type B, is at the top level a nominal projection. That is, instead of (30), I propose the following for the type B gerund:

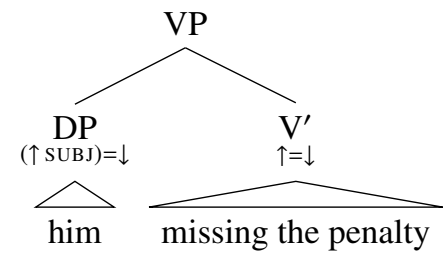

Differences of theory aside, this is similar to the proposal of Pires (2001, 2006, 2007), according to which the type B gerund (his "clausal gerunds") projects to a TP at the top level. What remains to be accounted for, under this proposal, is the identical distribution of gerunds and noun phrases. Under proposals where both 
type $\mathrm{B}$ and $\mathrm{C}$ gerunds are mixed projections, nominal at the top level, their distribution falls out naturally. If this distribution is not accounted for by categorization, it must be accounted for in some other way. Within a Minimalist framework, Pires (2007) assumes that the type B gerund, analysed as a TP, has the distribution of a noun phrase because it is assigned a Case feature which requires checking.

A similar approach could be taken within the LFG framework adopted here; for example type B gerunds could be lexically associated with a specification requiring the presence of a case feature at f-structure, which could only be supplied if the gerund phrase occurred in a relevant argument position. However, such an approach would not generalize to the analysis of participial clauses, discussed in the next section, which I analyse as verb phrases which share their distribution with adjectival and other modifying phrases.

I therefore adopt the same analysis proposed for the Arabic masdar above: if we distinguish the grammar, as a set of constraints on structures, from the structures themselves, then it is unproblematic to capture the identical distribution of type B gerund and noun phrases, by defining a metacategory which ranges over both phrase types, for example:

$$
\text { NomP } \equiv\left\{\mathrm{DP} \quad \mid \quad \mathrm{VP}_{[\text {ger }]}\right\}
$$

This constraint captures the nominal distribution of the type B gerund just as well as a mixed projection analysis involving a DP node, but has the advantage that it does not require that DP node to appear in the structure itself, accounting for the differences between the types $\mathrm{B}$ and $\mathrm{C}$ gerunds mentioned above. If both types have the same mixed projection structure, then these differences cannot easily be accounted for, but if the former is a mixed, partially nominal, projection, while the latter is a purely verbal projection, the differences fall out naturally. Of course, a set of phrase-structure rules which accurately models the distribution of noun phrases and gerunds is likely to require more than one metacategory which generalizes over these two types of phrase and one or more other phrase types. For example, one of the possible positions in which DPs and 
gerunds may appear, the subject position SpecIP, may also host phrases of other lexical categories, including APs, PPs and CPs:

a. Slowly is the best way to do it.

b. Is slowly the best way to do it?

c. Under the chair is a good place to hide it.

d. Is under the chair a good place to hide it?

e. Whether he knows is not relevant.

f. Is whether he knows relevant?

Examples (36b,d,f) show that the position of the relevant phrases in $(36 \mathrm{a}, \mathrm{c}, \mathrm{e})$ is SpecIP, rather than a position further to the left. ${ }^{24}$ Thus the phrase-structure rule which makes generalizations over the SpecIP position will most appropriately be stated using a metacategory which ranges over at least the categories DP, AP, PP, $\mathrm{CP}$ and $\mathrm{VP}_{\text {[ger] }}$. In contrast, the phrase-structure rule which makes generalizations over the core direct object position (first complement of V) will most appropriately be stated using a metacategory which ranges over DP, CP and $\mathrm{VP}_{[\text {ger] }}$, but not AP and PP. ${ }^{25}$

[24] There are constraints on the appearance of CPs in subject position (the 'internal-S constraint' of Ross 1967), including the impossibility of auxiliary inversion with some subject CPs (for a summary of the relevant evidence, see McCawley 1998: 325-331):

i. $\quad$ a. *Is that he fell over unexpected?

c. *How unexpected was that he fell over.

This is taken by many, including Bresnan et al. (2016: 15-19), as evidence that CPs cannot appear in SpecIP but, when functioning as subjects, appear in a higher, adjoined position. That this cannot apply to all CPs is clear from (36e-f), suggesting that the internal-S constraint may be best analysed as a processing constraint, as originally proposed by Ross (1967), and further developed e.g. by Grosu \& Thompson (1977).

[25] As with the subject position, Bresnan et al. (2016: 18) argue that finite complement clauses cannot be objects and that the core direct object position is restricted to DP (which on their view, includes all gerunds, as long as all gerunds are mixed projections). Their evidence for this is that complement clauses cannot become passive subjects, but this is not true for all complement clauses in English:

i. $\quad$ a. The committee did not debate whether this was a good thing.

b. Whether this was a good thing was not debated.

c. The committee did not consider why he had come.

d. Why he had come was not considered by the committee.

e. They soon forgot that he had previously criticized them.

f. That he had previously criticized them was soon forgotten.

Thus if passivization is restricted to objects, at least some CPs must be able to function as objects. 
Thus metacategory definitions have considerable use in the grammar, to model restrictions on phrase types in different positions, and therefore their use for mixed projections does not constitute an additional complication.

Beside the empirical evidence in favour of a structural distinction between type $\mathrm{B}$ and type $\mathrm{C}$ gerunds, there is also a theoretical argument. I argued above that exocentricity can be analysed as a marked possibility, cross-linguistically, which may be understood in terms of constraints which, all else being equal, rule out exocentric structures, including mixed projections. ${ }^{26}$ Therefore a grammar which necessitates fewer exocentric structures may be preferred, all else being equal. As there is no evidence specifically favouring the mixed (and therefore exocentric) analysis of the type B gerund, it seems fair to conclude that all else is equal, and that the exocentric, mixed projection, analysis of the type B gerund is to be dispreferred. This claim extends well beyond the analysis of the English gerund, of course. It entails that in all instances in which there is a difference between the distribution and the internal syntax of a particular phrase type, it is better not to analyse this in terms of a mixed projection, but rather assume an endocentric, internally consistent projection for the phrase itself, and to account for its distribution by other means.

To summarize my proposals for the English gerund, then: first, the type $\mathrm{C}$ gerund (poss-ing) is a true mixed projection, as evidenced by its mixed internal syntax. This can be modelled in LFG by means of a head-sharing structure, as proposed by Bresnan (1997) and shown in (37).

[26] Note that this is an observation about phrase structure, which is overwhelmingly frequently endocentric, and not a claim that e.g. nominalizations, and other constructions which display (functional) properties of more than one category, are in any sense unnatural or marked. 
(37)

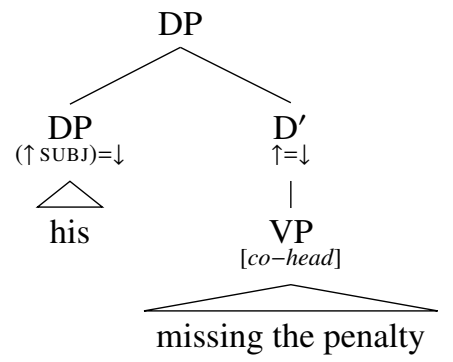

Second, the type B gerund, under which heading I include both structures with an 'accusative' case subject (acc-ing) and those with no explicit subject, are not mixed projections, but pure verbal projections which share their distribution with that of noun phrases. They are formed like any other verb phrase, with the exception of the VP-internal subject, which is lexically licensed by the gerund form of the verb.

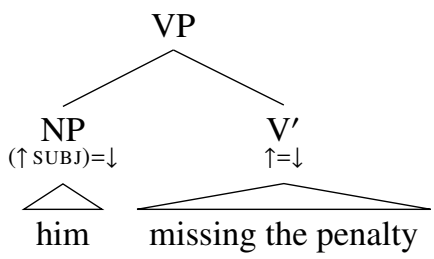

As a full illustration, I give the relevant phrase structure rule, metacategory definition, lexical entry and c-/f-structure representation for the sentence in (25b).

(39) $\quad$ IP $\rightarrow \quad$ SpecIP $\quad I^{\prime}$

$$
(\uparrow \mathrm{SUBJ})=\downarrow \quad \uparrow=\downarrow
$$

(40) $\operatorname{SpecIP} \equiv\left\{\mathrm{DP}\left|\mathrm{V}_{\text {[ger] }}\right| \mathrm{AP}|\mathrm{PP}| \mathrm{CP}\right\}$

(41) missing $V_{\text {[ger] }}$

$$
\begin{aligned}
& (\uparrow \text { PRED })=\text { 'miss }\langle\text { SUBJ, OBJ }\rangle \\
& (\uparrow \text { SUBJ CASE })=\text { ACC } \\
& (\uparrow \text { VFORM })=\text { GERUND }
\end{aligned}
$$




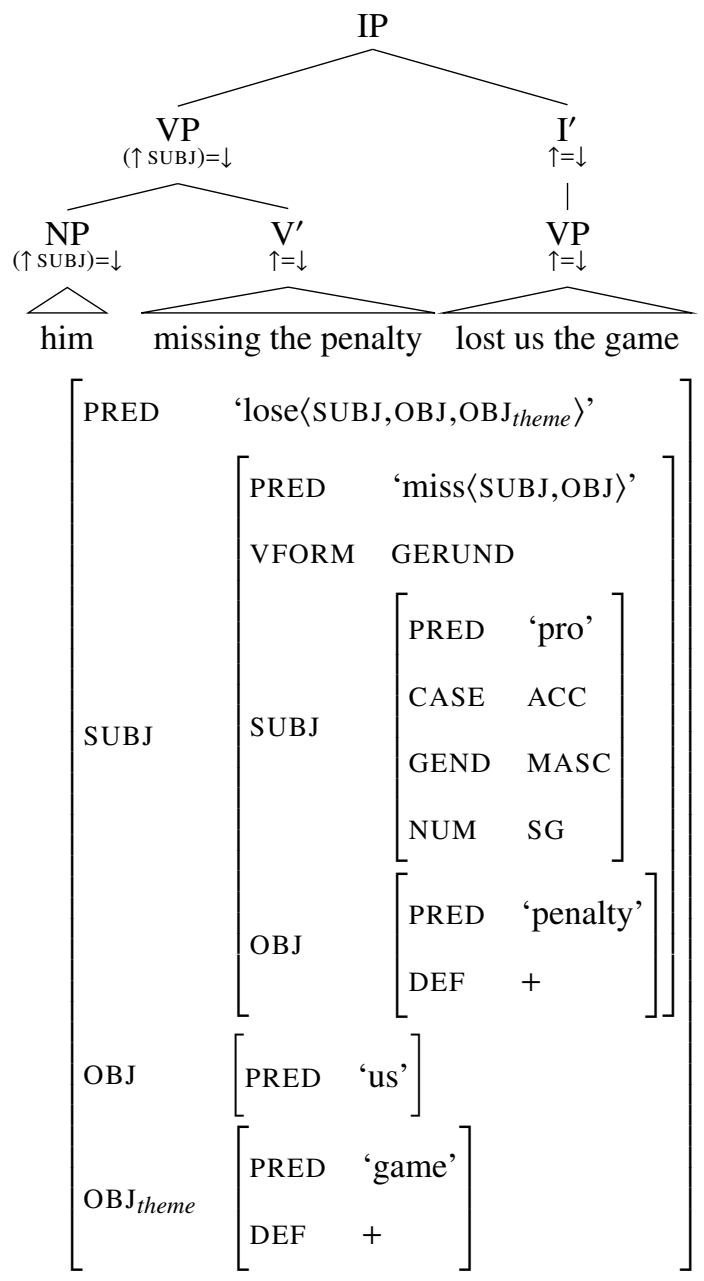

\section{AtTRIBUtive PARTICIPLES}

The evidence of the Arabic masdar suggested that distribution is neither a sufficient nor a necessary criterion for syntactic categorization, whereas internal syntax is crucial for categorization. The evidence of the English gerund supports this, insofar as an analysis in which the type B gerund is not a mixed projection fares better in accounting for the syntactic differences between type B and type C. The case of attributive participles is similar, but also brings into question the importance of the third criterion for categorization given in (2), morphosyntactic 
properties.

\subsection{Another mixed projection?}

Spencer (2015) discusses "Indo-European type" participles in Sanskrit, as treated by Author (2015), and also in Lithuanian, proposing an analysis that is in many respects the same as that proposed for German participles by Bresnan (1997: 2-3). All these participles are diachronically related, and are of the same 'subject-oriented' type; that is, to the extent that an attributive participial clause can be treated as a reduced relative clause, it is necessarily the subject that is relativized on. The participle agrees with and attributively modifies a noun, which is identified with the gapped subject of the participial clause. Ex. (43) shows an attributive participle in Sanskrit, (44) one from Lithuanian, and (45) one from German.

(43) sárasvatī sādháyantī dhíyạ̣ nạ S.NOM.SG perfect.PTC.PRS.ACT.NOM.SG.F thought.ACC.SG us.GEN 'Sarasvatī who perfects our thought' (Sanskrit)

(44) ateisiančios žiemos ilgumo

come.PTC.FUT.ACT.GEN.SG.F winter.GEN.SG length 'the length of the coming winter' (Lithuanian, from Spencer 2015: ex. 3)

(45) ein mehrere Sprachen sprechender Mann a several language.PL speak.PTC.NOM.SG.M man.NOM.SG 'A man who speaks several languages' (German, cited by Bresnan 1997: 2 from Drijkoningen 1992: 55)

These participles can also have other uses. For example, as discussed by Author (2015), Sanskrit participles can also be used predicatively, that is in 'converbal' or clausal adjunct use. The attributive use is the most canonically adjectival use of participles, but adjectives can also, to a slightly more limited extent, be used as clausal adjuncts, so in both uses participles appear to display adjectival distribution. I focus on attributive participles here, following Spencer (2015) and Bresnan (1997). 
Morphologically, participles are mixed in the sense that they combine a verbal stem with an adjectival suffix. Distributionally, they are at least superficially most similar to adjectives. However, the internal syntax of the participle phrase is exclusively verbal. Participles to transitive verbal stems may take objects, in the same case as, and entirely indistinguishable from, the object of a corresponding finite verb form; accusative case objects appear in (43) and (45). Likewise, participles may be modified by adverbs, but never by adjectives. Considering the three criteria defined in (2), the English type B gerund is purely verbal in respect of two of the three criteria, while attributive participles are purely verbal only in relation to one of the three:

\begin{tabular}{|l|c|c|c|}
\hline & Internal Syntax & Distribution & Morphosyntax \\
\hline Arabic masdar & mixed & nominal & nominal \\
Eng. B Gerund & verbal & nominal & verbal \\
Eng. C Gerund & mixed & nominal & verbal \\
Participles & verbal & adjectival & mixed \\
\hline
\end{tabular}

Spencer (2015) assumes that the adjectival distribution and mixed morphosyntactic properties of attributive participles justify a mixed projection analysis. Spencer notes that this could be formalized by means of the standard head-sharing approach seen with the type $\mathrm{C}$ English gerund above (i.e. in this case, a VP embedded within an AdjP), but he proposes an alternative, intermediate category analysis. Spencer (2015) adopts the morphological model of Spencer (2013), adapted to LFG, involving a semantic argument structure representation in the morphology of a word which maps to c- and f-structure and (among other things) determines the category of the word. The argument structure of a verb has an event semantic function (SF) role EV, while adjectives have a modifier SF role A-MOD. The morphological process that derives (or inflects) a participle from a verb creates a composite $\mathrm{SF}$ role $\langle\mathrm{S}-\mathrm{MOD}\langle\mathrm{EV}\rangle\rangle$. This composite SF role projects to c- and f-structure in such a way that participles 
display both adjectival and verbal morphosyntax. In terms of syntactic category, Spencer (2015) proposes that the composite SF role maps to an intermediate category, which he labels 'V2A' (for 'verb-to-adjective transposition').

$$
\text { Ex. (43), following Spencer (2015): }
$$

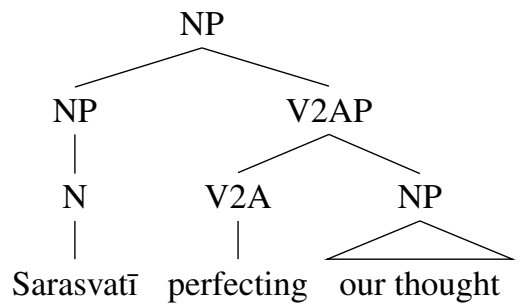

As it stands, this intermediate category approach is unsatisfactory within LFG, since the specifically verbal and specifically adjectival features of the category must be stipulated. LFG has no equivalent to the multiple inheritance hierarchy utilized by Malouf (2000) within HPSG to model a truly intermediate category gerund; thus 'V2A' is not, formally, intermediate between $\mathrm{V}$ and $\mathrm{Adj}$, but is simply a third category, fully distinct from both. It must therefore be stipulated that V2A has the internal syntax of V and the distribution of Adj, since it cannot fall out naturally from any principle of intermediate category formation. As Spencer (2015) notes, however, the mixed projection analysis of attributive participles could equally be modelled in terms of head-sharing. The situation is therefore parallel to Bresnan et al.'s (2016) analysis of the English gerund: a phrase with purely verbal internal syntax is treated as a mixed projection because it shows non-verbal distribution and, in this case, non-verbal morphology.

\subsection{Distribution}

In Sanskrit, participle phrases used attributively have essentially the same distribution as adjective phrases used attributively. But this is because the two types of phrase share attributive functionality, not necessarily because they share the same syntactic category. Other types of phrase can also function as attributive modifiers, in Sanskrit as well as in other languages with the same type of participle, e.g. Lithuanian and German. Most obviously, CPs headed by relative 
pronouns can function as attributive modifiers:

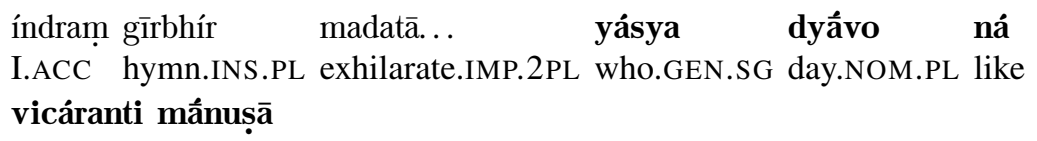

It would theoretically be possible to treat even attributive CPs as mixed

projections, projecting AdjP at the top level. ${ }^{27}$ But then the same issues arise as

with the English gerund discussed above: we can capture a distributional

generalization in the rules of the grammar in a way that licenses exocentric

phrase structures, or we can capture the generalization equally well but in a way

that licenses smaller and purely endocentric phrase structures. ${ }^{28}$

I therefore assume that the simplest analysis for participle phrases in languages

like Sanskrit, English and Lithuanian is a plain VP, as proposed by Author

(2015), with no mixed projection required:

[27] Alternatively, a separate 'attributive' category could be proposed as the top level projection for all attributive adjective phrases, participial phrases, CPs etc. For example, Struckmeier \& Kremers (2014) propose a functional head ' $\mathrm{C}(\mathrm{ase}) \mathrm{G}$ (ender)N(umber)-C' to provide a unified account of attributive modification in German. This would suffer from the same problems as the uniform AdjP account, in fact within LFG it would require exocentricity for every attributive structure, since the head is never lexically filled (in Struckmeier \& Kremers's model, it can be filled by agreement morphemes, but this could not be the case in LFG).

[28] When we look beyond attributive functionality, we find that participial phrases and adjective phrases do not necessarily display identical distribution. In early Sanskrit, for example, participles and adjectives share much of their distribution, both being able to function as attributive modifiers and as clausal adjuncts, but as discussed in detail in Author (2015), they differ fundamentally in that adjectives, but not participles, can freely occur as primary clausal predicates (with explicit or null copula). Equivalent considerations apply to participle phrases in Lithuanian and English. But the point is relatively moot: at most participles and adjectives show identical distribution, at least their distribution overlaps, but even if their distribution is identical, it is not necessary to assume that participles are mixed projections with $\mathrm{Adj} P$ at the top level. 
(49) Ex. (43), following Author (2015):

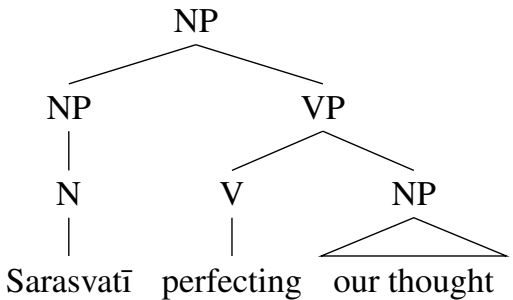

As with the English gerund VP, the participial VP can be treated as a subtype of VP, modelled by means of a complex category $\mathrm{V}_{[\mathrm{ptc}]}$. The distribution of participial VPs will be constrained by metacategory definitions parallel to (23) above. However, Spencer's (2015) argument that participle phrases should be treated as at least partially categorially adjectival is not based on distribution alone, but also on the third criterion used for categorial status in LFG: morphosyntactic agreement features.

\subsection{Morphology and agreement}

Superficially, it does not seem unreasonable to assume that agreement and similar morphosyntactic properties provide evidence of categoriality. In languages with rich morphological systems, some features are typically expressed on verbs, and others on nouns and adjectives. Tense, aspect and mood are prototypically verbal features, while definiteness is prototypically nominal. In terms of agreement, many Indo-European languages, including those discussed in the previous section, typically mark person and number on verbs, and case, number and gender on nouns and adjectives: thus person is a feature of verbal morphosyntax, and case and gender features of nominal and adjectival morphosyntax. However, while it is true that such patterns can be typical, even highly regular, in a language or even many languages, such patterns need not be absolute. Even cross-linguistically regular tendencies may have exceptions; for example, Nordlinger \& Sadler (2004a, b) discuss languages in which tense features can be marked on nominals. ${ }^{29}$ But within languages too, there are often 
exceptions to the typical division of morphosyntactic labour between nouns and verbs. In fact many such exceptions involve categories remarkably similar to the sorts of categories under discussion in this paper.

In particular, it is not uncommon for unequivocal finite verb categories to show 'adjectival' or 'nominal' agreement in some languages, in cases where non-finite verbal categories such as participles or agent nominalizations have become grammaticalized and integrated into the finite verbal paradigm. For example, finite present and future verb forms in Russian and other Slavic languages mark person and number, but past tense verbs, marked with the formant $-l-$, agree rather in gender and number. The gender/number morphology of past tense verbs in Russian is more similar to that of nouns and adjectives that to the person/number marking on non-past verbs. Diachronically, the reason for this is that the past tense in $-l$ - derives from a construction involving a verbal adjective in *-lo-, which in the development of the Slavic languages replaced the inherited finite past tenses (which, like the present, marked person and number). At some point in the pre-history of Slavic, the forms in $-l$ - must have been categorial adjectives, as they were in the ancestor of Slavic, Proto-Indo-European. Now, however, there is no justification for analysing the past tense formation in $-l$ - as anything other than fully verbal. Many languages attest equivalent developments, including for example many Indo-Aryan languages, where the (often ergative) perfective aspect derives from what is in early Sanskrit a verbal adjective.

What phenomena like this show is that diachronic developments may lead to the recategorization of a particular formation, without necessitating any corresponding morphosyntactic reformation. When verbal adjectives are reanalysed as finite verbs, their adjectival agreement requirements need not immediately be replaced by verbal agreement. When a verbal adjective is integrated into a verbal paradigm, it will likely adopt some verbal feature marking, e.g. tense or mood, but its existing agreement features may continue to exist alongside this. Over time, it may well be that analogical pressure results in changes to the paradigm which bring it more closely in line with the rest of the 
paradigm; an example of this is the integration of what was originally a noun into the verbal system as the 'aorist passive' formation in Sanskrit (Kümmel 1996). Alternatively, the integrated formation may simply preserve its original paradigmatic oppositions (e.g. gender/number agreement), which therefore become oppositions relevant to the verbal system, rather than simply relevant to the nominal or adjectival system. ${ }^{30}$ Thus from a diachronic perspective, it is problematic to assume that morphosyntax necessarily tells us anything about the synchronic status of a formation. If a verb form happens to show adjectival agreement, this need not be because it is synchronically an adjective, since it could equally be that it was adjectival at an earlier period and that its syntactic category has changed while its agreement features have not.

The example of the Russian past tense in - $l$ - involves a verbal adjective being reanalysed as a finite verb. The course of development of the verbal adjective is too remote to trace, but $*$-lo- is not reconstructed as a participle for Proto-Indo-European, since in other Indo-European languages the descendants of *-lo- form not participles but lexical adjectival derivatives from verbal roots. ${ }^{31}$ Thus at some point an Adj was reanalysed as a V. It is not necessarily the case, however, that the reanalysis as $\mathrm{V}$ was concomitant with the reanalysis as a finite verb form. It is equally possible that inherited *-lo- was first reanalysed as a participle, a non-finite verbal form, and recategorized as $\mathrm{V}$, and that the reanalysis as a finite formation was later. In the case of participles of the type found in Sanskrit, German and Lithuanian, which are non-finite verb forms with verbal internal syntax but adjectival agreement, we see forms that have undergone the first development, but which have not undergone the second. ${ }^{32}$

[30] There may be additional pressures at work, for example TAM oppositions may be harder to adopt into a nominal paradigm than into a verbal paradigm, but I make no claims on this point here. It is also important to distinguish agreement from the expression of features inherent to the word concerned. For example, there may be a tendency against nouns expressing tense, so if a verb is nominalized tense expression is likely to be lost, but if an adjective becomes a verb, there is nothing against the verb indicating gender, even if verbs don't have gender, because the gender is not an inherent feature of the adjective/verb, but of the element the adjective/verb is agreeing with.

[31] For *-lo- in Proto-Indo-European see Meier-Brügger (2003: 285) and Rau (2009: 72).

[32] To the extent that periphrastic constructions such as the Lithuanian progressive can be analysed 
That is, if non-finite verb categories such as participles, gerunds and infinitives are (or at least can be) of category $\mathrm{V}$, it must be possible for adjectives and nouns which become reanalysed as part of a language's non-finite verb system to be recategorized as Vs, without necessarily losing their nominal or adjectival morphosyntax. In the case of Sanskrit, Lithuanian and German participles, comparative evidence suggests an ultimately adjectival origin, although the details are too remote to be secure (Author 2015: 311-316).

However, going beyond the fact that diachronic change can obscure otherwise neat correlations between category and morphosyntax, Spencer (2015) argues that in purely synchronic morphological terms it should not be an accident that in languages such as Sanskrit and Lithuanian participles show exactly the same agreement features, and even paradigms, as lexical adjectives. This is a fair claim. However, in a grammatical framework like LFG, where different types of grammatical information are represented at different levels of structure, there is no reason why morphological patterns should necessarily be reflected in the constituent structure, which models primarily constituency relations. The morphological similarities between a finite verb showing, say, gender/number marking and a historically related noun or adjective category with gender/number marking may be relevant, and could be modelled, at the morphological level, and may also be relevant at the level of functional structure, since e.g. the feature GENDER may appear in all f-structures headed by a word which marks gender, whether verb or noun. But to further propagate morphological patterns into the representation of constituent structure is superfluous.

Spencer's (2015) argument that participles are categorially adjectival (at least in part) due to their adjectival morphosyntax depends on the assumption that the morphological feature(s) shared between adjectives and participles necessarily influence the syntactic category of a word. In Spencer's model, this is true, since it is the adjectival semantic function role A-MOD in the argument structure 
representation of a lexeme that determines both agreement properties, and syntactic category. However, there is no reason why this should necessarily be the case: it is perfectly conceivable that agreement properties and syntactic category be determined separately. In Author (2016) I provide a formal model of word formation within LFG which captures the morphological similarities between participles and adjectives in terms of shared properties at the morphological level, but which also permits participles and adjectives to be realized with distinct syntactic categories outside the morphological component. For reasons of space I omit the details of the morphological model here. However it is worth considering the output of the morphology, i.e. the syntactic similarities and differences between adjectives and participles, under my proposal.

$$
\begin{aligned}
& \text { sādháyantī } \quad V_{\text {[ptc] }} \\
& (\uparrow \text { PRED })=\text { perfect }\langle\text { SUBJ,OBJ }\rangle \\
& (\uparrow \text { TENSE-ASP })=\text { PRESENT } \\
& (\uparrow \text { VOICE })=\text { ACTIVE } \\
& (\uparrow \text { VFORM })=\text { PTC } \\
& (\uparrow \text { AGR NUM })=\text { SG } \\
& (\uparrow \text { AGR GEND })=\text { FEM } \\
& (\uparrow \text { AGR CASE })=\text { NOM } \\
& (\uparrow \text { AGR })=(\uparrow \text { SUBJ AGR })
\end{aligned}
$$

(52) sắdhanā Adj

$(\uparrow \mathrm{PRED})=$ 'perfecting'

$(\uparrow$ AGR NUM $)=$ SG

$(\uparrow \mathrm{AGR}$ GEND $)=$ FEM

$(\uparrow$ AGR CASE $)=$ NOM

$(\uparrow \mathrm{AGR})=(\mathrm{ADJ} \in \uparrow \mathrm{AGR})$
(51) sādháyati $V_{\text {[fin] }}$ $(\uparrow \operatorname{PRED})={ }^{\prime} \operatorname{perfect}\langle$ SUBJ, OBJ $\rangle '$

$(\uparrow$ TENSE-ASP $)=$ PRESENT

$(\uparrow$ VOICE $)=$ ACTIVE

$(\uparrow \mathrm{VFORM})=\mathrm{FIN}$

$(\uparrow \mathrm{AGR} N \mathrm{NU})=\mathrm{SG}$

$(\uparrow$ AGR PERS $)=3$

$(\uparrow \mathrm{AGR})=(\uparrow \mathrm{SUBJ}$ AGR $)$

Ex. (50) shows the lexical entry for the nom.sg.fem. participle sādháyantī 'perfecting'; (51) shows the lexical entry for the finite 3sg. verb form sādháyati 'perfects'; and (52) shows the lexical entry for the derived adjective sâdhanā 'perfecting' (nom.sg.fem.). As a part of the inflectional verbal paradigm, 
sādháyantī inherits the same PRED value as the finite verb, including its subcategorization requirements, which accounts for its appearance with an object. ${ }^{33}$ The participle also inherits verbal tense-aspect and voice features for the same reason. However, participles and finite verbs are specified as separate subtypes of the category verb, $\mathrm{V}_{\text {[ptc] }}$ and $\mathrm{V}_{\text {[fin] }}$ respectively. The subcategory of participles inherits, alongside its verbal features, also the agreement features typical of adjectives, modelled here using an AGR feature; thus both the participle and adjective specify number, gender and case features. Both words also have a specification determining which element is agreed with; the participle, as a verb form, inherits the same specification as the finite verb, agreeing with its subject, while the adjective inherits the adjective-only specification that it agrees with the element it modifies.

In this way, the participle in (50) inherits and displays both verbal and adjectival properties, as we would expect. But crucially, the adjectival properties of the participle do not require a distinct Adj node in its c-structure projection; rather, it can be unproblematically treated as a subcategory of $\mathrm{V}$, its distribution captured by means of a metacategory. As with the English gerund, this is a positive result, because the analysis captures the data just as adequately as a mixed projection analysis would do, but without the requirement for an exocentric structure. In the default case, where distribution and internal syntax align, differences in agreement properties are not sufficient to justify separate categorization; for example, for imperfective and perfective verb forms in Hindi, or non-past and past forms in Russian, there is widespread agreement that these are all Vs, and that the differences between the two types are relevant at the morphological and f-structure levels, but not in the c-structure. We have here been considering a more complex case, where distribution and morphology pattern together in opposition to internal syntax. As argued in detail in the preceding sections,

[33] The lexical entries are abbreviated, of course; additional shared specification will determine e.g. the case of the object; the identification of the participle's subject with the element it modifies is achieved via constructional specifications (since participles can be used in more than one function), and are therefore not part of the lexical entry of the participle. 
where internal syntax and distribution conflict, it is analytically problematic to privilege distribution over internal syntax. Thus the logical conclusion is that morphosyntactic properties (or agreement properties, at least) must also be subordinate to internal syntax as a criterion for categorization.

\section{CONSEQUENCES FOR CATEGORIZATION}

Within the confines of this paper it is not possible to consider in detail the wider consequences of the proposals made in earlier sections on the basis of the evidence of (apparent) mixed projection phenomena. In this section I aim to summarize and sketch out how an approach to categorization which privileges internal syntax might work in general, rather than just in the case of mixed projections. The basic idea is schematized in (53).

\begin{tabular}{|c|c|c|c|c|c|}
\hline \multirow[t]{2}{*}{ int. syntax: } & \multicolumn{2}{|c|}{ identical } & \multicolumn{2}{|c|}{ subset } & mismatch \\
\hline & & $\downarrow$ & & $\downarrow$ & $\downarrow$ \\
\hline \multirow[t]{2}{*}{ distr/morph: } & same & different & same & different & $\downarrow$ \\
\hline & $\downarrow$ & $\downarrow$ & $\downarrow$ & $\downarrow$ & $\downarrow$ \\
\hline \multirow[t]{2}{*}{ category: } & same & \multicolumn{2}{|c|}{ subcategory } & \multicolumn{2}{|c|}{ different } \\
\hline & (a) & (b) & (c) & (d) & (e) \\
\hline
\end{tabular}

The analyses presented in the preceding sections suggest an implicative relationship between internal syntax and categorization. Given the proposal that internal syntax is the primary criterion for distinguishing between categories, it follows that distinct syntactic categories have distinct internal syntax. This amounts to the claim that sets of phrases with the same internal syntactic possibilities are part of the same syntactic category. It is on this basis, for example, that the shared internal syntactic possibilities of (at least most) common nouns, i.e. adjectival modification, determiners, etc., permit the category $\mathrm{N}$ to be postulated. This corresponds to (a) in (53).

It does not follow, however, that sets of phrases with differing internal syntax are 
necessarily of different categories, nor that distribution (and perhaps morphosyntax) is irrelevant to categorization in the case where a set of phrases shows the same internal syntax. To take the second point first, where a set of words shares the same internal syntactic possibilities, but falls into two or more distinct classes in terms of distribution (which is likely to correlate also with a difference in morphology), these distinct subclasses can be treated as subcategories of one another. This is the case, for example, with the distinction between finite verbs and the type B English gerund: they share the same internal syntax, but differ in distributional terms. By classifying gerund verb phrases as $\mathrm{V}_{\text {[ger] }}$, their distinct distribution can be unproblematically captured, as described above. This corresponds to (b) in (53).

If two sets of phrases do not share the same internal syntax, the situation is more complicated, because there are different ways in which phrases may differ in this respect. Certain sets of phrases may have mutually exclusive internal syntactic possibilities, in which case they must belong to completely separate categories, regardless of their distribution. This is the case, for example, with ordinary noun phrases and gerund phrases: each set shows internal syntax which is excluded for the other set, and on this basis they must be distinct categories, despite sharing the same distribution. This corresponds to (e) in (53).

It is also possible, however, that a set of phrases may display only a subset of the internal syntactic possibilities of another set of phrases. Hudson (2003) argues, entirely contrary to the position proposed in this paper, that internal syntax cannot be relevant to categorization, since e.g. personal pronouns share none of the internal syntactic possibilities of noun phrases (being unable to be modified, take complements, etc.). Similarly, intransitive verbs show only a subset of the internal syntactic possibilities that transitive verbs have. Yet it is possible to treat transitive and intransitive verbs as subcategories of the same category $\mathrm{V}$, based on their shared distributional and morphosyntactic properties. Likewise, personal pronouns can be treated as a subcategory of noun, based on their shared distribution. This corresponds to (c) in (53). 
Finally, some sets of phrases show a subset of the internal syntactic possibilities of another phrase type, while also differing in distributional and morphological terms. Preposition phrases in English show some of the same feature of internal syntax as transitive verb phrases, for instance, being able to govern object complements, and undergo adverbial (pre)modification. On the other hand adverbial postmodification, and postmodification by PPs, is excluded for PPs, but not for transitive VPs. Purely in terms of internal syntax, this is parallel to the difference between intransitive and transitive verbs, but crucially PPs differ distributionally and morphologically from VPs, justifying a distinct category. This corresponds to (d) in (53).

Considerably more space would be required to work out and demonstrate that such an approach to categorization can be generally applied crosslinguistically, maintaining at least in large part the major category distinctions generally assumed. Nevertheless, I would argue that the evidence of mixed projections, as presented in this paper, implies a more general approach to categorization as sketched in this section.

\section{Conclusion}

The proposal that internal syntax is a sufficient and necessary criterion for syntactic categorization implies that there are identifiable internal syntactic distinctions between the major categories. For instance, it becomes a matter of principle that verbs (and adpositions) may take objects but that nouns and adjectives may not. We also derive a clear definition of a mixed projection: if a phrase shows internal syntactic properties of two categories, it is mixed; if it does not, it is not. Thus the type C English gerund, transitive adjectives in Sanskrit, and the Arabic masdar are mixed categories, but the type B English gerund, and Sanskrit participles, are not. On the other hand, if distribution and morphosyntax are given equal or greater weight as criteria for categorization, there is no longer any clear way to define mixed projections or to assess when one is or is not dealing with one. 
In this paper I have examined the criteria used as evidence for category status in mixed projection analyses proposed within LFG, a grammatical framework which is fundamentally 'distributionalist' (Kornfilt \& Whitman 2011), i.e. which relies primarily on syntactic evidence for category status. The most clearly mixed phrases are those where the internal syntax of the phrase is itself mixed. A number of mixed projection proposals have been made, however, for phenomena where there is no evidence for mixed internal syntax, but where there is merely a mismatch between the internal syntax and the distribution and/or morphosyntax of the phrase. I have shown that distribution and morphosyntax are not primary criteria for categoriality, and thus proposed that such 'mismatched' categories (e.g. participles) are best not analysed as mixed projections. This leaves internal syntax as the primary syntactic criterion for determining syntactic category. The extent to which such an approach may be sufficient for categorization more generally, or whether it in fact supports a non-syntactic approach to categorization (an 'essentialist' approach), remains to be explored more fully in future work.

\section{REFERENCES}

Abney, Steven. 1987. The English Noun Phrase in its Sentential Aspect: MIT dissertation.

Alexiadou, Artemis, Gianina Iordăchioaia \& Florian Schäfer. 2011. Scaling the variation in Romance and Germanic nominalizations. In Petra Sleeman \& Harry Perridon (eds.), Noun phrase in Romance and Germanic: structure, variation and change, 25-40. Amsterdam: Benjamins. Alsharif, Ahmad. 2014. The syntax of negation in Arabic: University of Essex dissertation. Arnold, Doug \& Louisa Sadler. 2013. Displaced dependent constructions. In Miriam Butt \& Tracy Holloway King (eds.), Proceedings of the LFG13 Conference, 48-68. Stanford, CA: CSLI Publications.

Asudeh, Ash. 2012. The Logic of Pronominal Resumption. Oxford: Oxford University Press.

Baker, Mark C. 2003. Lexical Categories: Verbs, Nouns, and Adjectives. Cambridge: Cambridge University Press.

Blackburn, Patrick \& Claire Gardent. 1995. A Specification Language for Lexical Functional Grammars. In Proceedings of the Seventh Conference of the European Chapter of the Association for Computational Linguistics, 39-44. Association for Computational Linguistics.

Bögel, Tina. 2015. The syntax-prosody interface in lexical functional grammar: Universität Konstanz dissertation. 
Börjars, Kersti, Safiah Madkhali \& John Payne. 2015. Masdars and mixed category constructions. In Miriam Butt \& Tracy Holloway King (eds.), Proceedings of the LFG15 Conference, 26-42.

Stanford, CA: CSLI Publications.

Borsley, Robert D. \& Jaklin Kornfilt. 2000. Mixed extended projections. In Robert D. Borsley (ed.), The nature and function of syntactic categories, 101-131. New York: Academic Press.

Bresnan, Joan. 1997. Mixed categories as head sharing constructions. In Miriam Butt \& Tracy Holloway King (eds.), Proceedings of the LFG97 Conference, Stanford, CA: CSLI Publications.

Bresnan, Joan. 2000. Optimal syntax. In Joost Dekkers, Frank van der Leeuw \& Jeroen van de Weijer (eds.), Optimality Theory: Phonology, syntax and acquisition, 334-385. Oxford: Oxford University Press.

Bresnan, Joan. 2001. Lexical-functional syntax. Oxford: Blackwell.

Bresnan, Joan, Ash Asudeh, Ida Toivonen \& Stephen Wechsler. 2016. Lexical-functional syntax. Oxford: Wiley-Blackwell. Second edition. First edition by Joan Bresnan, 2001, Blackwell.

Bresnan, Joan \& John Mugane. 2006. Agentive nominalizations in Gĩkũyũ and the theory of mixed categories. In Miriam Butt, Mary Dalrymple \& Tracy Holloway King (eds.), Intelligent linguistic architectures: Variations on themes by Ronald M. Kaplan, 201-234. Stanford, CA: CSLI Publications.

Butt, Miriam \& Tracy Holloway King. 1997. Null elements in discourse structure. MS, University of Konstanz. http://ling.uni-konstanz.de/pages/home/butt/main/papers/nulls97.pdf.

Butt, Miriam \& Tracy Holloway King. 1998. Interfacing phonology with LFG. In Miriam Butt \& Tracy Holloway King (eds.), Proceedings of the LFG98 Conference, Stanford, CA: CSLI Publications.

Butt, Miriam, Tracy Holloway King, María-Eugenia Niño \& Frédérique Segond. 1999. A grammar writer's cookbook. Stanford, CA: CSLI Publications.

Chomsky, Noam. 1981. Lectures on Government and Binding: The Pisa lectures. Dordrecht: Foris. Dalrymple, Mary. 2001. Lexical Functional Grammar. San Diego, CA: Academic Press.

Dalrymple, Mary, Ronald M. Kaplan \& Tracy Holloway King. 2015. Economy of expression as a principle of syntax. Journal of Language Modelling 3(2). 377-412.

Dalrymple, Mary, John Lamping, Fernando Pereira \& Vijay Saraswat. 1996. A deductive account of quantification in LFG. In Makoto Kanazawa, Christopher J. Piñón \& Henriette de Swart (eds.), Quantifiers, deduction and context, 33-57. Stanford, CA: CSLI Publications.

Dalrymple, Mary \& Louise Mycock. 2011. The prosody-semantics interface. In Miriam Butt \& Tracy Holloway King (eds.), Proceedings of the LFG11 Conference, 173-193. Stanford, CA: CSLI Publications.

Dalrymple, Mary \& Irina Nikolaeva. 2011. Objects and information structure. Cambridge: Cambridge University Press.

Drijkoningen, Frank. 1992. Derivation in syntax. In Mark Aronoff (ed.), Morphology now, 48-68. Albany, NY: SUNY Press.

Fassi Fehri, Abdelkader. 1993. Issues in the structure of Arabic clauses and words. Dordrecht: Kluwer Academic. 
Grimshaw, Jane. 1990. Argument structure. Cambridge, MA: MIT Press.

Grimshaw, Jane. 1991. Extended projections. MS, Brandeis University.

Grimshaw, Jane. 2000. Locality and extended projection. In Peter Coopmans, Martin Everaert \& Jane Grimshaw (eds.), Lexical specification and insertion, 115-134. Amsterdam: Benjamins.

Grosu, Alexander \& Sandra A. Thompson. 1977. Constraints on the distribution of NP clauses. Language 53(1). 104-151.

Hamm, Fritz \& Michiel van Lambalgen. 2005. Formal foundations for semantic theories of nominalization. ZAS Papers in Linguistics 27. 1-21.

Haug, Dag T. T. \& Tanya Nikitina. 2016. Feature sharing in agreement. Natural Language \& Linguistic Theory 34. 865-910.

Hristov, Božhil P. 2013. Pronominal case assignment in English. Journal of Linguistics 49(3). 567-611.

Hudson, Richard A. 2003. Gerunds without phrase structure. Natural Language \& Linguistic Theory 21. 579-615.

Jackendoff, Ray. 1977. X Syntax: A Study of Phrase Structure. Cambridge, MA: MIT Press.

Kaplan, Ronald M. 1987. Three seductions of computational psycholinguistics. In P. Whitelock,

M. M. Wood, H. L. Somers, R. Johnson \& P. Bennett (eds.), Linguistic theory and computer applications, 149-181. London: Academic Press. Also in Formal Issues in Lexical-Functional Grammar, ed. Mary Dalrymple, Ronald M. Kaplan, John T. Maxwell III and Annie Zaenen, CSLI Publications, 1995, pp. 339-367.

Kaplan, Ronald M. 1989. The Formal Architecture of Lexical-Functional Grammar. In Chu-Ren Huang \& Keh-Jiann Chen (eds.), ROCLING II: Proceedings of the Computational Linguistics Conference, 3-18. Tapei: The Association for Computational Linguistics and Chinese Language Processing (ACLCLP). Also published in Journal of Information Science and Engineering 5 (1989), pp. 305-322, and in Formal Issues in Lexical-Functional Grammar, ed. Mary Dalrymple, Ronald M. Kaplan, John T. Maxwell III and Annie Zaenen, CSLI Publications, 1995, pp. 7-27. Kaplan, Ronald M. \& Joan Bresnan. 1982. Lexical-Functional Grammar: A Formal System for Grammatical Representation. In Joan Bresnan (ed.), The Mental Representation of Grammatical Relations, 173-281. Cambridge, MA: MIT Press.

Kaplan, Ronald M. \& Annie Zaenen. 1989. Long-distance dependencies, constituent structure, and functional uncertainty. In Mark R. Baltin \& Anthony S. Kroch (eds.), Alternative conceptions of phrase structure, 17-42. Chicago: University of Chicago Press.

King, Tracy Holloway. 1997. Focus Domains and Information-Structure. In Miriam Butt \& Tracy Holloway King (eds.), Proceedings of the LFG97 Conference, Stanford, CA: CSLI Publications.

King, Tracy Holloway. 2016. Theoretical linguistics and grammar engineering as mutually constraining disciplines. In Doug Arnold, Miriam Butt, Berthold Crysmann, Tracy Holloway King \& Stefan Müller (eds.), Proceedings of the HeadLex16 conference, 339-359. Stanford, CA: CSLI Publications.

Kornfilt, Jaklin \& John Whitman. 2011. afterword: Nominalizations in syntactic theory. Lingua 121. 1297-1313. 
Kümmel, Martin Joachim. 1996. Stativ und Passivaorist im Indoiranischen Historische

Sprachforschung: Ergänzungheft 39. Göttingen: Vandenhoeck \& Ruprecht.

Lapointe, Steven G. 1993. Dual lexical categories and the syntax of mixed category phrases. In A. Kathol \& M. Bernstein (eds.), Proceedings of the Eastern States Conference on Linguistics, 199-210. Ithaca, NY: Cornell University.

Malouf, Robert. 1996. A constructional approach to English verbal gerunds. In Proceedings of the twenty-second annual meeting of the Berkeley Linguistics Society: General session and parasession on the role of learnability in grammatical theory, 255-266. Berkeley: Berkeley Linguistics Society.

Malouf, Robert. 2000. Mixed categories in the hierarchical lexicon. Stanford, CA: CSLI Publications.

Marcotte, Jean-Philippe. 2014. Syntactic categories in the correspondence architecture. In Miriam Butt \& Tracy Holloway King (eds.), Proceedings of the LFG14 Conference, 408-428. Stanford, CA: CSLI Publications.

Maxwell, Jr III, John T. \& Ronald M. Kaplan. 1994. The interface between phrasal and functional constraints. Computational Linguistics 19(4). 571-590.

McCawley, James D. 1998. The syntactic phenomena of English. Chicago: University of Chicago Press 2nd edn.

Meier-Brügger, Michael. 2003. Indo-European Linguistics. Berlin: De Gruyter.

Mugane, John M. 1996. Bantu nominalization structures: University of Arizona, Tucson dissertation.

Musan, Renate. 1997. Tense, predicates, and lifetime effects. Natural Language Semantics 5. 271-301.

Mycock, Louise. 2006. The Typology of Constituent Questions: A Lexical-Functional Grammar analysis of 'wh'-questions: University of Manchester dissertation.

Nikitina, Tatiana V. 2008. The mixing of syntactic properties and language change: Stanford University dissertation.

Nikitina, Tatiana V. \& Dag T. T. Haug. 2016. Syntactic nominalization in Latin: a case of non-canonical subject agreement. Transactions of the Philological Society 114(1). 25-50.

Nordlinger, Rachel \& Louisa Sadler. 2004a. Tense beyond the verb: Encoding clausal tense/aspect/mood on nominal dependents. Natural Language \& Linguistic Theory 22(3). 597-641.

Nordlinger, Rachel \& Louisa Sadler. 2004b. Nominal tense in crosslinguistic perspective. Language 80(4). 776-806.

Panagiotidis, E. Phoevos. 2010. Nonargumental mixed projections. Syntax 13. 165-182.

Panagiotidis, E. Phoevos. 2015. Categorial features: a generative theory of word-class categories. Cambridge: Cambridge University Press.

Payne, John, Rodney Huddleston \& Geoffrey K. Pullum. 2010. The distribution and category status of adjectives and adverbs. Word Structure 3(1). 31-81.

Pires, Acrisio. 2001. The syntax of gerunds and infinitives: subjects, case and control: University of Maryland dissertation. 
Pires, Acrisio. 2006. The minimalist syntax of defective domains: gerunds and infinitives.

Philadelphia: Benjamins.

Pires, Acrisio. 2007. The derivation of clausal gerunds. Syntax 10(2). 165-203.

Pollard, Carl J. 1996. The nature of constraint-based grammar. Paper presented at the Pacific Asia Conference on Language, Information, and Computation, Kyung Hee University, Seoul, Korea. http://lingo.stanford.edu/sag/L221a/pollard-96.txt.

Pullum, Geoffrey K. 2007. The evolution of model-theoretic frameworks in linguistics. In James Rogers \& Stephan Kepser (eds.), Model-theoretic syntax at 10 (proceedings of the mts10 workshop, august 13-Ü17, organized as part of ESSLLI 2007), 1-10. Dublin: Trinity College Dublin.

Pullum, Geoffrey K. \& Barbara C. Scholz. 2001. On the distinction between model-theoretic and generative-enumerative syntactic frameworks. In Philippe de Groote, Glyn Morrill \& Christian Retoré (eds.), Logical aspects of computational linguistics: 4th international conference (lecture notes in artificial intelligence, 2099), 17-43. Berlin: Springer.

Rau, Jeremy. 2009. Indo-European Nominal Morphology: The Decads and the Caland System. Innsbruck: Institut für Sprachen und Literaturen der Universität Innsbruck.

Ross, John Robert. 1967. Constraints on variables in syntax: MIT dissertation.

Ryding, Karin C. 2005. A reference grammar of Modern Standard Arabic. Cambridge: Cambridge University Press.

Sadler, Louisa \& Doug Arnold. 1994. Prenominal adjectives and the phrasal/lexical distinction. Journal of Linguistics 30. 187-226.

Seiss, Melanie. 2008. The English -ing form. In Miriam Butt \& Tracy Holloway King (eds.), Proceedings of the LFG08 Conference, 454-472. Stanford, CA: CSLI Publications.

Spencer, Andrew. 2004. Towards a typology of mixed categories. In C. Orhan Orgun \& Peter Sells (eds.), Morphology and the web of grammar: Essays in memory of Steven G. Lapointe, Stanford, CA: CSLI Publications.

Spencer, Andrew. 2013. Lexical relatedness: A paradigm-based approach. Oxford: Oxford University Press.

Spencer, Andrew. 2015. Participial relatives in LFG. In Miriam Butt \& Tracy Holloway King (eds.), Proceedings of the LFG15 Conference, 378-398. Stanford, CA: CSLI Publications.

Struckmeier, Volker \& Joost Kremers. 2014. On the properties of attributive phrases. In Petra Sleeman, Frank van de Velde \& Harry Perridon (eds.), Adjectives in Germanic and Romance, Amsterdam: Benjamins.

Toivonen, Ida. 2003. Non-projecting words: A case study of Swedish verbal particles. Dordrecht: Kluwer.

Tonhauser, Judith. 2005. Towards an understanding of the meaning of nominal tense. In Emar Maier, Corien Bary \& J. Huitnink (eds.), Proceedings of Sinn und Bedeutung 9, 475-488. Nijmegen: Nijmegen Centre of Semantics.

Tonhauser, Judith. 2007. Nominal tense? the meaning of Guarani nominal temporal markers. Language 83. 831-869. 
Wescoat, Michael T. 1994. Phrase structure, lexical sharing, partial ordering, and the English gerund. In Proceedings of the Twentieth Annual Meeting of the Berkeley Linguistics Society: General Session dedicated to the contributions of Charles J. Fillmore, 587-598. Berkeley, CA: Berkeley Linguistics Society. 
Author's address: 